\title{
The Inland Sea: Circulation of Chesapeake Bay and the Northern Adriatic
}

\author{
W.C. Boicourt, M. Kuzmić, and T.S. Hopkins
}

\begin{abstract}
Despite obvious differences in the scale and aspect ratio of their basins, the Chesapeake Bay and the Northern Adriatic Sea share similar histories of nutrient enrichment, and similar nutrient pathways. Buoyancy and nutrients are delivered by a primary source located at the landward end of elongated, enclosed, coastal body of water. This geometry encourages thermohaline circulations that act to retain water-borne materials and thereby set the stage for possible eutrophication. Deciphering nutrient pathways within these slowly varying circulations might be comparatively straightforward were it not for the often dominating presence of wind-driven motions. In the Northern Adriatic, winds with identities--Bora and Sirocco-rule the circulation during their visits. Even in the face of strong stratification, winds mix the shallow water columns of both the Chesapeake and Northern Adriatic, occasionally to the point of homogeneity. Air-sea interactions associated with these winds alter the density structure of both systems, but in the Adriatic, they drive an important thermohaline circulation.

Quantitative assessment of various nutrient management strategies will require an improved understanding of the details of circulation pathways throughout the seasonal progression of atmospheric forcing and of buoyancy and nutrient inputs in both water bodies. Crucial questions remain, many of which center on physical-biological interactions in the vertical dimension. In the Northern Adriatic, a key question is the mechanism and degree of lateral transport of water and nutrients out of the Po River plume and into the interior. In both the Chesapeake Bay and the Northern Adriatic, a coupled physical-biological model would greatly aid the attack on these problems. Analytical efforts in Chesapeake Bay have been supported by a rich set of synoptic and time-series measurements. Similar modeling efforts in the Northern Adriatic have progressed without the benefit of this level of observation, but the pace of future advancements will hinge on obtaining this information.
\end{abstract}

Ecosystems at the Land-Sea Margin: Drainage Basin to Coastal Sea

Coastal and Estuarine Studies Volume 55, Pages 81-129

Copyright 1999 by the American Geophysical Union 


\section{Introduction}

Transport processes exert control at key phases of oceanic nutrient cycles, from the initial delivery to regulation of vertical distributions. While a detailed understanding of these mechanisms would substantially aid our ability to decipher nutrient dynamics and their role in global climate, it is in the coastal ocean that the need for an accurate quantitative description is especially acute. Here, society is faced with decisions regarding restoration of enriched waters, decisions made difficult by uncertainty in which inputs are controllable, where the restoration target should be, and what effects management actions will have on the ecosystem. Unfortunately, small shifts in these lines of demarcation have large implications in the associated costs of restoration and preservation.

A shared environmental concern has motivated a comparison between the Chesapeake Bay and the Northern Adriatic Sea. The obvious intent in this search is to exploit similarities and differences to gain insight into the workings of the ecosystem. The hope is that some new order might emerge from the multitude of complex, concurrent, and interacting processes controlling nutrient pathways and regulating vertical exchange. But when we first bring our pictures of the Chesapeake Bay and the Northern Adriatic Sea together, the differences seem so great that this comparison appears, if not strained, at least not promising of insight.

The most obvious difference between these two water bodies is the scale and aspect ratio of the basin. For nutrients, this scale disparity results in some important differences in the mode of delivery and retention. The pace and pattern of vertical transport and mixing, key controls on ecosystem processes, can also vary significantly. While the adjacent continental shelf insulates the Chesapeake Bay from the nearby Gulf Stream and associated anticyclonic eddies, the Northern Adriatic is insulated from the Atlantic Ocean by virtue of its position in the Mediterranean Sea, far from the Straits of Gibraltar. In the Chesapeake Bay and the Northem Adriatic, a unique mixture of sills, shoals, and lateral constrictions act as the agents for this insulation.

The seasonal progression of prevailing winds is noticeable in Chesapeake Bay's circulation, but in the Northern Adriatic Sea, the wind-driven motion is punctuated by winds sufficiently strong to warrant an identity: Bora and Sirocco. During these events, winds dominate the circulation and thermodynamics. Air-sea interactions can significantly alter water mass characteristics in the Chesapeake, but in the Adriatic Sea, atmospheric exchange drives a significant thermohaline circulation. Here, net evaporation drives a flow opposing the estuarine-like circulation induced by buoyancy inputs from land. Tidal motions occur in both water bodies. But where the Adriatic, tides seem almost an afterthought, in the Chesapeake Bay, tides are of paramount importance, providing the primary energy source for the mixing that drives the classical estuarine circulation.

In spite of the obvious differences, there are sufficient suggestions of similarities to warrant a second look at these two systems. Such a look reveals that, fundamentally, nutrient pathways and circulation controls are similar. Buoyancy and nutrients are delivered by a primary source near the landward end of an elongated water body whose communication with the adjacent sea is far removed on the opposite end. Such a geometry encourages thermohaline circulation and retention, and sets the stage for possible eutrophication. This geometry also helps insulate the inner reaches from the influence of the adjacent sea. Furthermore, the enclosed nature of both basins allows free oscillations and a variety of constrained, atmospherically forced circulations. Although the deeper portions of the Adriatic 
Sea approach the depths of the continental slope, the Northern Adriatic depths are comparable to the central channels of the Chesapeake Bay. With similar depths and similar amounts of buoyancy input $\left(2300 \mathrm{~m}^{3} \mathrm{~s}^{-1}\right.$ for the Chesapeake and $2500 \mathrm{~m}^{3} \mathrm{~s}^{-1}$ for the Northern Adriatic), vertical advective and diffusive scales might be expected to be comparable. These scales are especially relevant to nutrient and phytoplankton dynamics.

Armed with these suggestions of similarity, as well as difference, we intend to explore circulation processes of the Chesapeake Bay and Adriatic Sea, seeking in this comparison to find hints of insight as well as to sharpen our research questions and reveal promising lines of investigation. We will limit our comparison to the Northern Adriatic, where the shallower depths allow such a juxtaposition. To the south, the Adriatic's depths approach oceanic scales, and diminish the prospect of fruitful effort. We are aided in this comparison attempt by existing reviews [Beardsley and Boicourt, 1981; Orlić, Gačić, and La Violette, 1992] and by recent work. We will begin with the Chesapeake Bay and, perhaps unconventionally, with the short time-scale variability. From there, we will progress to the mean circulation, and then to smaller spatial scales, and repeat the process in the Northern Adriatic Sea. Having surveyed both water bodies, we will then engage in a comparison and discuss outstanding questions on their circulation processes and nutrient pathways.

\section{Chesapeake Bay Circulation}

\section{Oceanographic Setting}

The drowning of the Susquehanna River valley by the rise in sea level that followed the Wisconsin ice age formed a long, narrow, and nearly straight Bay extending seaward $300 \mathrm{~km}$ from the present mouth of the River (Figure 1). The narrowness of the river valley created an estuarine cross section that resembles more a champagne glass than a bowl, with a central deep channel bordered by shallower shoulders. The distributions of area and volume with depth manifest the erosional history of the rivers cutting their path through coastal plain sediments (Figure 2). Both distributions are unimodal, producing a hypsographic curve that appears exponential. The hypsographic curve and the similar areal density curve break rapidly in the depth zone $13-15 \mathrm{~m}$, reflecting the incision of the river valley into the surrounding sedimentary layers, the erosional feature that forms the central channel of the Bay.

Though the paleochannel of the Susquehanna River can be traced from the present mouth of the Susquehanna River to the mouth of the estuary via subbottom profiling techniques (Figure 1; Colman et al., 1990], the central channel of the modern Chesapeake Bay does not remain uniformly deep. Extending over $120 \mathrm{~km}$ in the middle reaches of the Bay, the 'Deep Trough' has typical depths greater than $30 \mathrm{~m}$, and is the locus of summer oxygen depletion. Seaward of the Potomac River junction, channel depths decrease rapidly to $12 \mathrm{~m}$ over the broad and remarkably uniform Rappahannock Shoals. As the Bay widens further seaward, the main Chesapeake Channel and Thimble Shoals Channel deepen, but the lateral and central shoals become shallower. This lower Bay province of broad shoals interrupted only occasionally by a few channels stands in contrast to the narrow and deep northern and middle reaches.

The geometry of the Chesapeake Bay would steer and constrain the flow of even a nonrotating, homogeneous fluid. But an average $2300 \mathrm{~m}^{3} \mathrm{~s}^{-1}$ of fresh water is discharged to this 

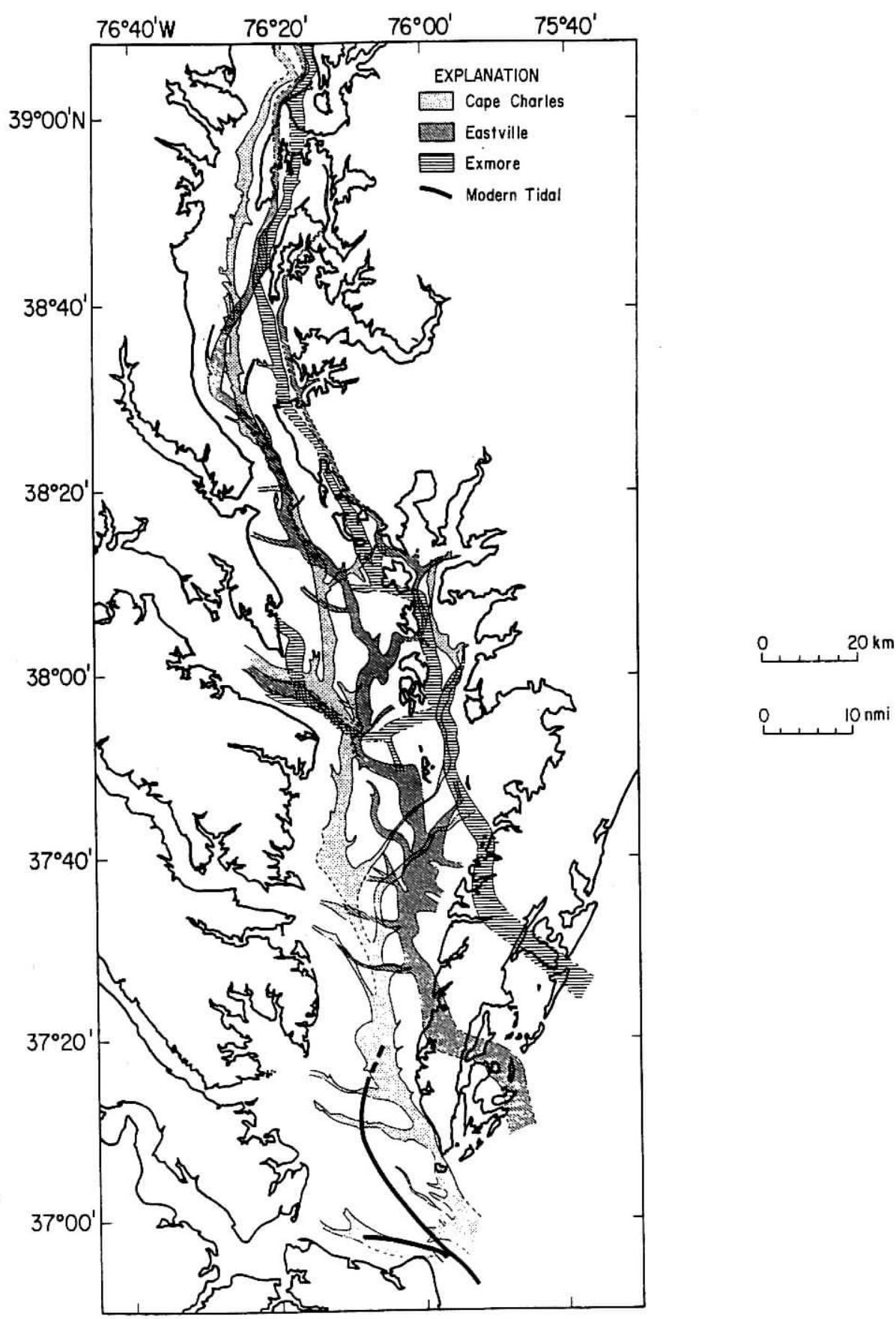

Figure 1a. Chesapeake Bay paleochannel distributions from three systems during the Quaternary (from Colman et al., 1990). 


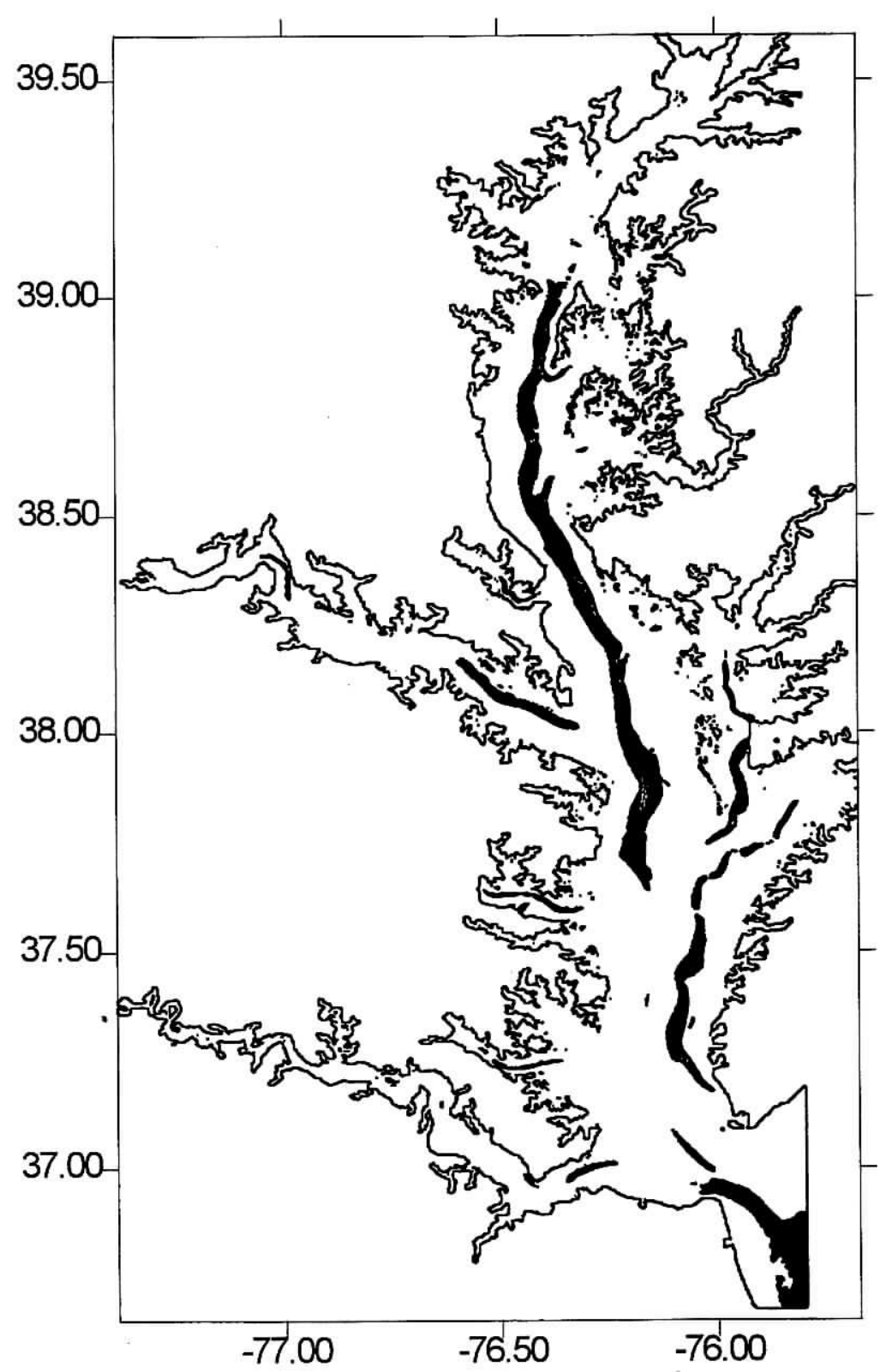

Figure 1b. Present channel locations. Shaded region indicates depths greater than $15 \mathrm{~m}$. 


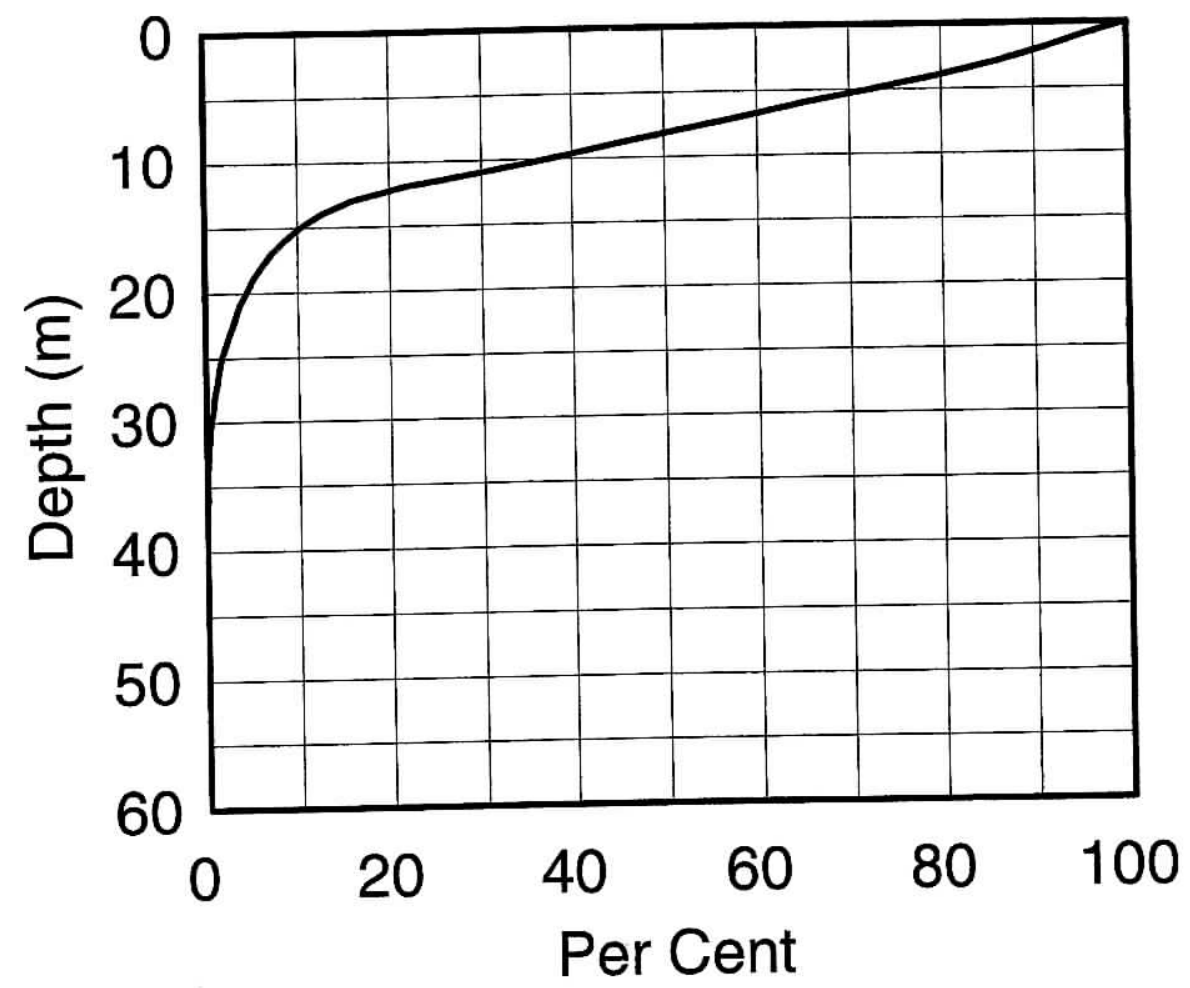

Figure 2a. Cumulative areal density curve for the main stem of Chesapeake Bay. Data are from Cronin (1971).

long, narrow basin connected to the Middle Atlantic Bight continental shelf [Schubel and Pritchard, 1986]. This source constitutes approximately half the water in the Bay, while the other half originates in the adjacent sea. The outcome of this meeting is the strong stratification and thermohaline flow of the classical estuarine circulation. The interaction of this flow with the topography is complex, especially when we add the oscillatory motion of the tide. Nonuniformities in the longitudinal direction create hydraulic controls, basin retentions, sill processes, and eddies (behind shoals or headlands) and fronts. Near the head of both the main stem Bay and its tributaries, turbidity maxima are created by the interaction of longitudinal convergences in the estuarine flow and tidal resuspension. With a Rossby radius of order $5 \mathrm{~km}$, variations in width along the axis of the Bay allow the formation of rotationally trapped coastal currents within the confines of the estuary. These coastal currents are fostered by the injection of buoyant water by the Potomac, Rappahannock, York, and James Rivers on the western shore of the Bay, punctuating the seaward flow of the upper layer. In the lateral direction, the proximity of the Bay's pycnocline $(10-13 \mathrm{~m})$ to the topographic break between the central channel and the flanking shoulders sets up conditions for complex upwelling circulations and lateral internal tides, especially in the middle reaches. 


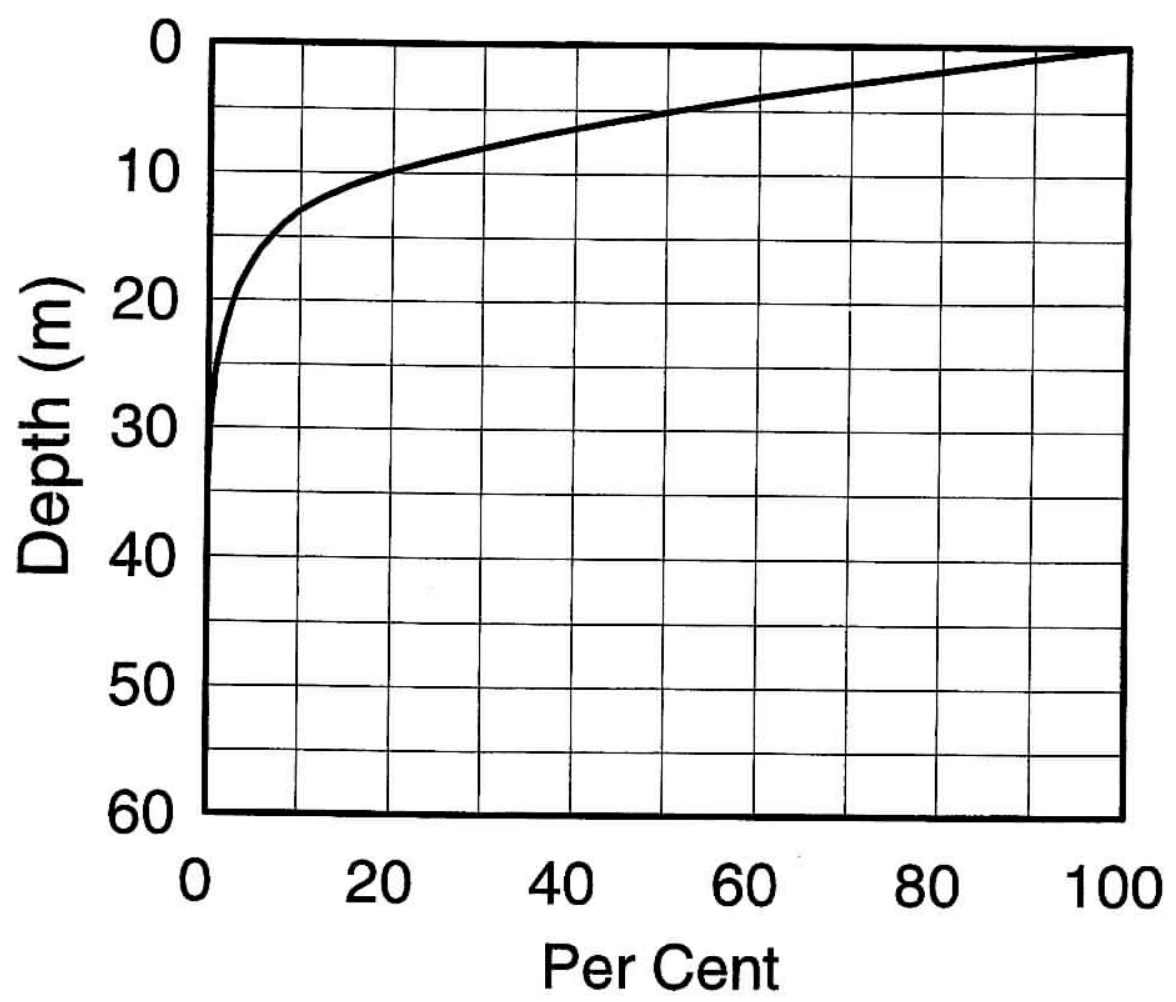

Figure 2b. Cumulative volume density, or hypsographic curve for the main stem of Chesapeake Bay. Data are from Cronin (1971).

While the buoyancy input from the Susquehanna River acts to unify the Bay's circulation, topographic features act to produce local and regional circulations, and thereby, spatially heterogeneous mixing. These circulations, which in turn feed back into the transport and mixing processes of the Bay as a whole, will be discussed further in the section on topographic effects.

\section{Fresh Water Inflow}

The Susquehanna River, with an annual flow of $1099 \mathrm{~m}^{3} \mathrm{~s}^{-1}$, provides approximately half of the freshwater input to the Chesapeake Bay [Schubel and Pritchard, 1986]. But in the region north of the Potomac River junction the Susquehanna dominates, contributing $87 \%$ of the total input. The Potomac is the next largest river, with an annual average discharge of 310 $\mathrm{m}^{3} \mathrm{~s}^{-1}$, or $16 \%$ of the $2300 \mathrm{~m}^{3} \mathrm{~s}^{-1}$ total input to the Bay. After the James River, with $14 \%$ to the total [Bue, 1968], there is a sharp drop in contributions from individual rivers. The next largest river is the Rappahannock, which amounts to less than $4 \%$ of the total. In comparison to annual streamflow, evaporation and precipitation are small. Annual average rainfall in the 
Chesapeake region ranges from 80 to $120 \mathrm{~cm}$, while evaporation is typically $90-100 \mathrm{~cm}$. A net input (precipitation minus evaporation) of $25 \mathrm{~cm}$ would be equivalent to $67 \mathrm{~m}^{3} \mathrm{~s}^{-1}$, or $3 \%$ of the total annual average streamflow to the Bay [Boicourt, 1969]. However, during summer, low streamflow conditions, evaporation is expected to play a much more significant role in the water budget.

As is typical of mid-latitude rivers, the flow undergoes a regular seasonal progression, from the strong spring runoff from snow melt and spring rains to the lower flows during dryer seasons of summer and early fall. In the mean, this variation amounts to nearly an order of magnitude in range. Though many flow years mimic the modal year, any individual year can depart dramatically from this regular progression [Boicourt, 1969; Schubel and Pritchard, 1986].

\section{Tides and Free Oscillations}

The primary determinants of estuarine circulation are freshwater inflow, the geometry of the basin (especially the cross-sectional area), and the strength of the tide [Pritchard, 1967]. Tidal amplitude is employed as an index of the amount of energy available to mix fresh and salt water, although wind mixing has recently been shown to contribute significantly in estuaries with long fetches or with minimal tide (e.g. Goodrich et al., 1987]. The Chesapeake Bay is a partially mixed estuary, where mixing results in vertical transport of both salt and fresh water. In contrast to the Northern Adriatic, Chesapeake Bay tides and the associated mixing are fundamental to the understanding of its motions because tidal mixing produces the potential energy necessary to drive the classical estuarine circulation.

The regular semidiumal $\mathrm{M}_{2}$ tide propagates across the Middle Atlantic Bight with crests of the tidal wave parallel to the coast [Redfield, 1958]. The shelf tides are nearly in cooscillation with the incident tide from the North Atlantic Ocean, so that the maximum amplitude is near the coast, and the maximum current amplitude is at midshelf. The mean tidal range at Chesapeake Light Tower, $20 \mathrm{~km}$ from the entrance to the Chesapeake Bay, is $1.08 \mathrm{~m}$. In the first $70 \mathrm{~km}$ of tidal wave propagation in the Bay, tidal range decreases rapidly by half. Over the middle reaches of the Bay, the tide propagates without significant decrease, but with substantially greater tidal range on the eastern side, due to the rotation of the earth [Figure 3; Hicks, 1964; Browne and Fisher, 1988].

As the $\mathrm{M}_{2}$ tidal wave enters the Bay, it is nearly pure progressive, with phase differences between tidal height and current being of order $10^{\circ}$ [Hicks, 1964; Browne and Fisher, 1988]. The tidal wave then propagates up the Bay with a phase velocity of approximately $20 \mathrm{~km} \mathrm{~h}^{-1}$ (Figure 4). The Bay is sufficiently long to enclose an entire wavelength within its boundaries. Phase differences between height and current increase to a maximum of $30^{\circ}, 40 \mathrm{~km}$ from the entrance, then decrease to where the $M_{2}$ tide is nearly pure progressive for the next $160 \mathrm{~km}$. Toward the head of the Bay, a sufficient amount of reflection occurs to increase the tidal range and to shift the phase relationships toward a standing wave. If the $\mathrm{M}_{2}$ tide were propagating at the phase velocity for a shallow water gravity wave for the entire length of the Bay, then it would be moving in an equivalent water depth of $3 \mathrm{~m}$, considerably less than the $8.4-\mathrm{m}$ mean depth of the Bay. But in the northern Bay, the wave character changes to a partially standing wave. Over the central portion of the Bay where the wave is pure progressive, the $M_{2}$ tide propagates at $25 \mathrm{~km} \mathrm{~h}^{-1}$, with an equivalent depth of $5 \mathrm{~m}$. 


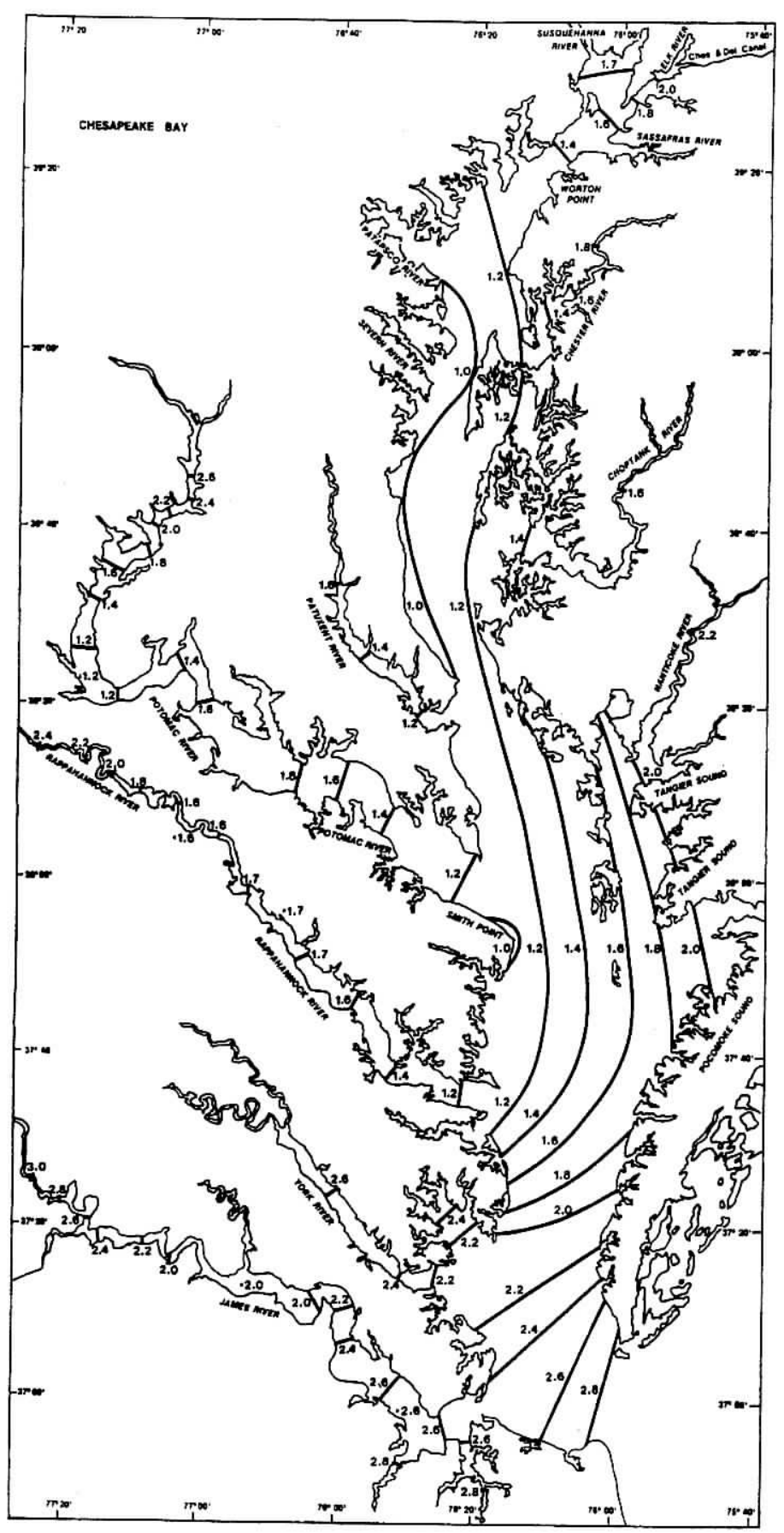

Figure 3. Tidal range (ft.) for whole tide in Chesapeake Bay, from Browne and Fisher (1988). 


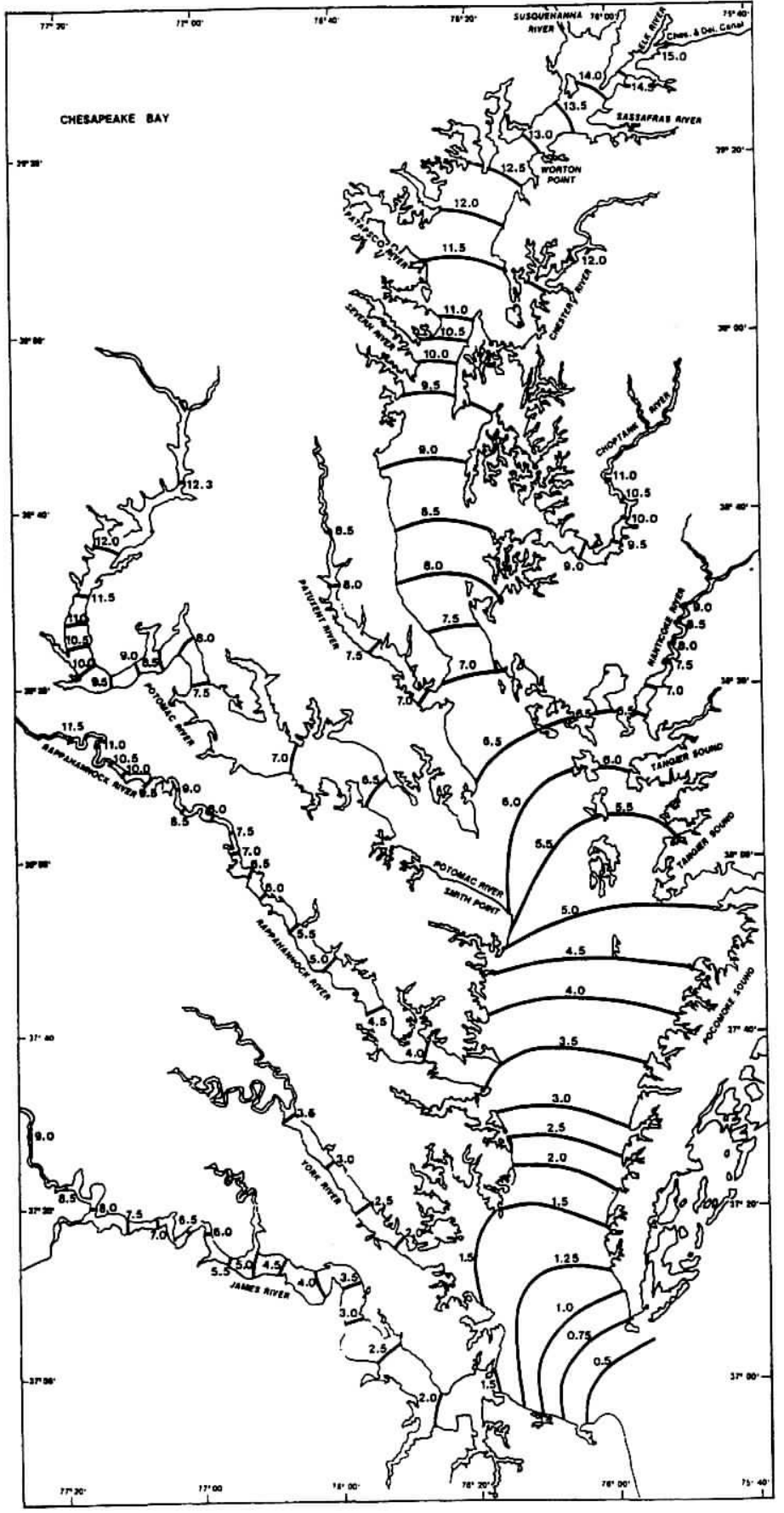

Figure 4. Co-phase lines for the $\mathrm{M}_{2}$ tide in Chesapeake Bay, from Browne and Fisher (1988). 
Browne and Fisher [1988] cited Parker's [1984] model of a frictionally damped tidal wave in a long shallow estuary to describe the $\mathbf{M}_{2}$ tide in Chesapeake Bay as a damped and partially reflected Kelvin wave, with two virtual amphidromes located over land to the west of the Bay. The virtual amphidrome of the $\mathrm{M}_{2}$ tide in the middle reaches of the Bay signifies the change in character of the tide along the Bay's axis. While the tide in the lower and upper Bay is regular semidiurnal, the greater relative contribution of diurnal tides within the $\mathbf{M}_{2}$ amphidrome creates mixed tides in the middle reaches.

Tidal currents moving over a hydrodynamically rough bottom have traditionally been invoked as the primary mixing mechanism for estuaries, although the details of these mixing processes have remained elusive. Turbulence is produced not only by shear flow in the bottom boundary layer, but also by the nonlinear generation of vorticity by oscillatory tidal flow over smaller scale features in the bottom topography [Zimmerman, 1978]. The superposition of the two-layer gravitational flow and the tide produces an asymmetry in stratification and mixing called tidal straining [Simpson, et al., 1990]. When the effects of wind mixing [Goodrich et al., 1987] and breaking internal waves [Brandt et al., 1986] are added, the complexity moves quickly to the point where partitioning the mixing among the candidate processes becomes difficult with the present state of knowledge.

In the Chesapeake Bay, the wealth of archived current measurements allows a comparatively detailed description of the tidal current field. The first-order picture of the tidal currents is that spatially, the amplitude of near-surface tidal currents varies with the amplitude of the tidal height, but with local increases at narrow cross-sections [Browne and Fisher, 1988]. Bottom friction acts to decrease current amplitude with depth, and to advance the phase of the near-bottom oscillations [Proudman, 1953]. This phase advance and upward phase propagation creates marked phase differences of tidal currents as the depth changes laterally across the Bay, with the shallows leading the center channel currents by as much as two hours (Figure 5).

Fortnightly variations in tidal strength have been shown to produce large neap-spring changes in stratification in the tributaries of the southern Bay [Haas, 1977], where tidal amplitudes are large. Hayward et al. [1982] and Ruzecki and Evans [1988] suggest that this process is likely complex, involving spatial gradients in tidal mixing and phased advection in tributary/main-stem interactions. Fortnightly variations in tidal mixing may be expected in other tributaries, such as in the lower Patuxent River in the northern Bay, or in the main stem, but they have not as yet been observed.

The unusually long, straight, and shallow basin of the Chesapeake Bay would appear favorable for free oscillations. Wang [1979] ascribed subtidal oscillations in Chesapeake Bay with periods of less than 4 days to wind-induced seiches. Both Vieira [1986] and Olson [1986] noticed oscillations in the 2-day band, but did not identify their origin. Chuang and Boicourt [1989] observed an unusually strong burst of quarter-wave seiche activity in the Bay in April, 1986, and suggested that the system was nearly in resonance. They determined that the nodal point of the seiche was located, not at the entrance to the Bay, but at an uncertain point approximately $30 \mathrm{~km}$ landward from the entrance. The quarter-wave seiche is now understood as the dominant subtidal variability in the Bay's circulation, and can be observed in water-level records or kinetic energy spectra at any season (Figure 6). As Goodrich [1988] points out, this mode of motion is likely to be a significant additional contribution to estuaryshelf exchange, supplementing exchange produced by the gravitational circulation and the tides. 


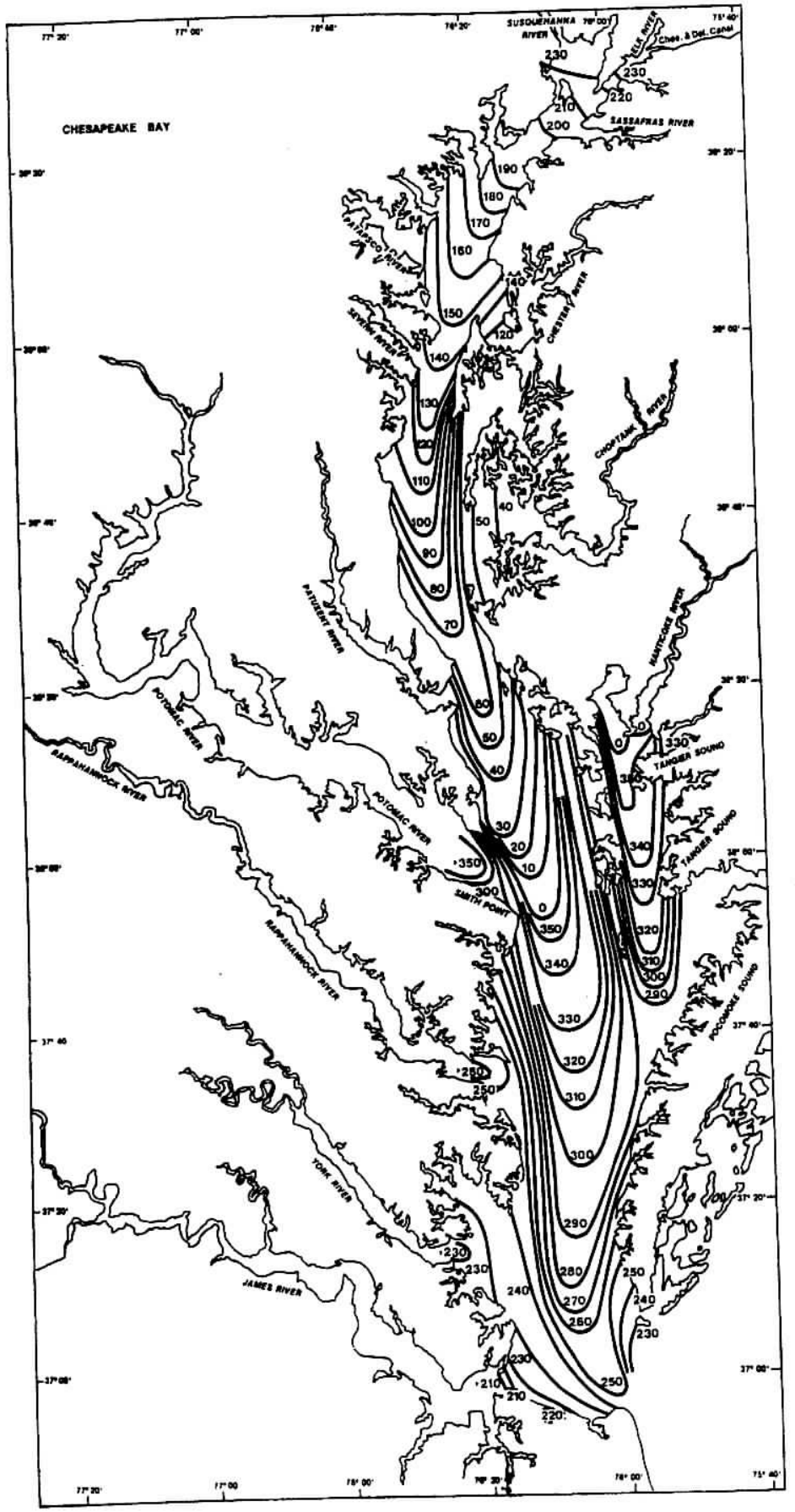

Figure 5. Co-phase lines for the $\mathrm{M}_{2}$ tidal current in Chesapeake Bay, from Browne and Fisher (1988). 


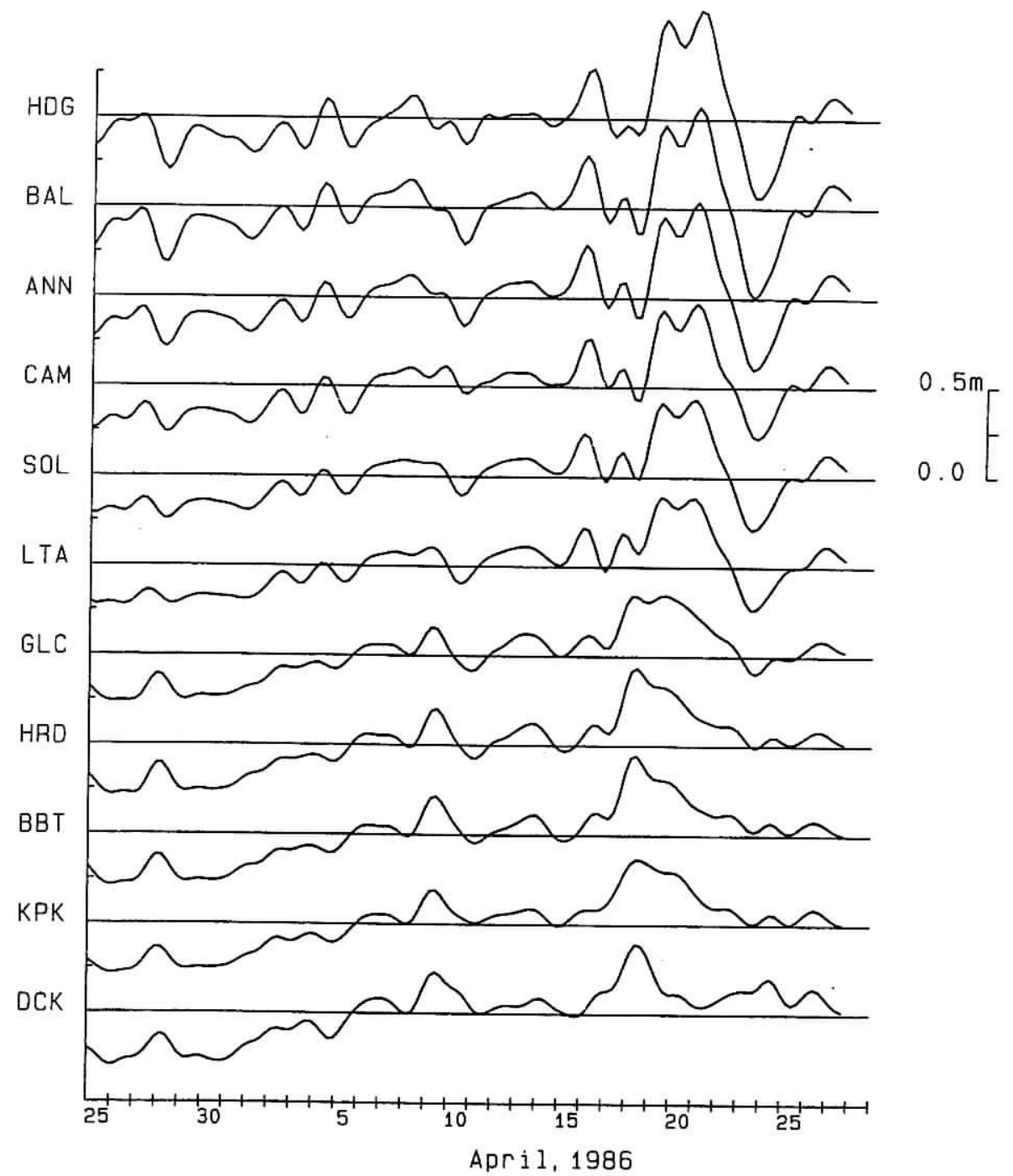

Figure 6a. Subtidal (low-pass filtered) water level records from Chesapeake Bay. Records are arranged from north-to-south geographic position. HDG is Havre de Grace, BAL--Baltimore, ANN-Annapolis, CAM-Cambridge, SOL-Solomons, LTA--Lewisetta, GLC--Gloucester, HRD--Hampton Roads, BBT--Bay Bridge Tunnel, KPK-Kiptopeake, and DCK-Duck, North Carolina.

\section{Wind Driven Circulation and Mixing}

The advent of reliable current meters in the late 1960's ushered in the era when researchers began to examine fluctuations about the classical estuarine circulation, which was presumed steady, or slowly varying. Of special interest was the direct and indirect response 


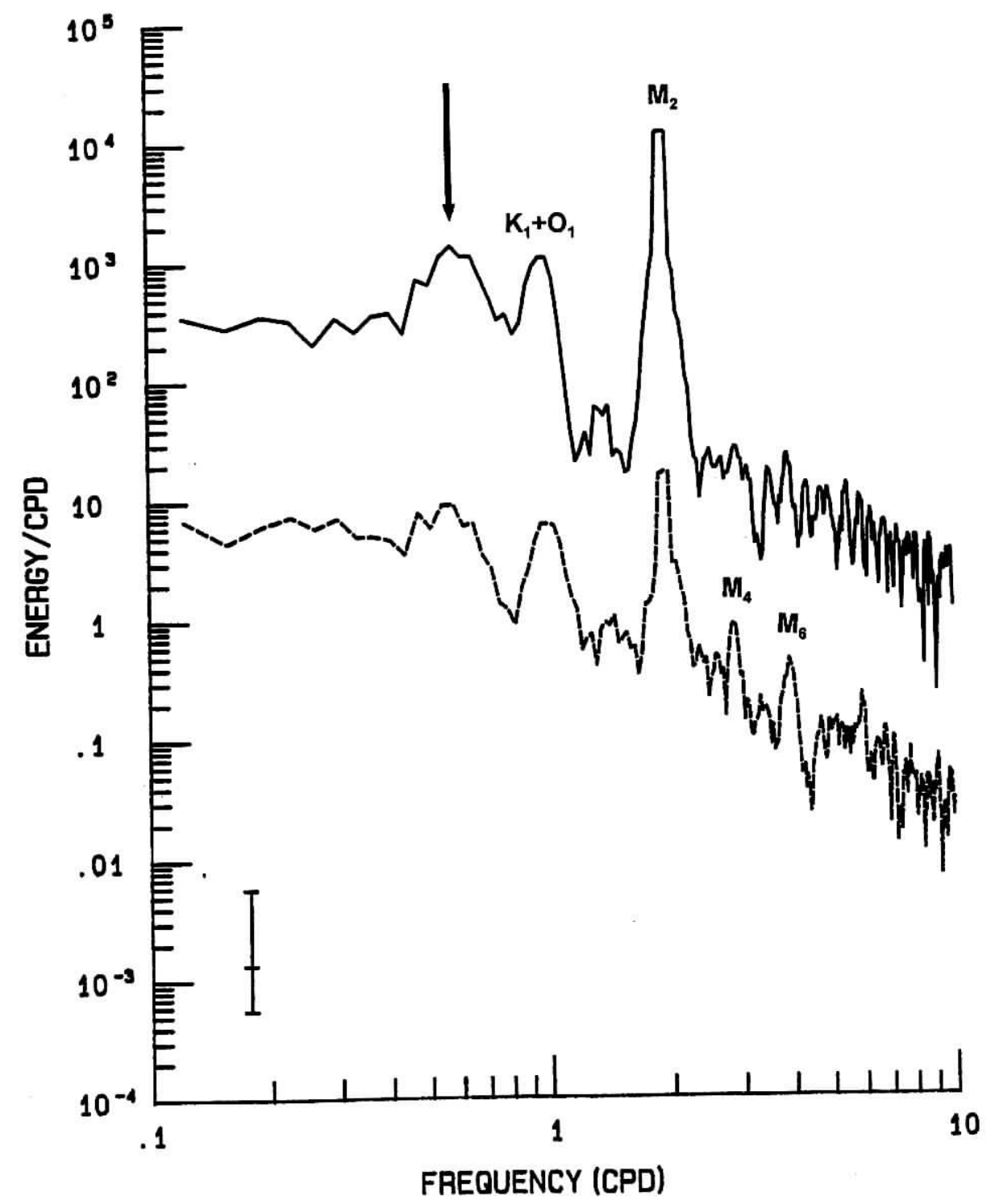

Figure 6b. Spectrum of velocity (solid line) and salinity (dashed line) from a current meter moored at $2.4 \mathrm{~m}$ depth at the entrance of Chesapeake Bay during April, 1986. Quarter-wave seiche peak is indicated by arrow. Diurnal $\left(K_{1}\right.$ and $\left.O_{1}\right)$, semidiurnal $\left(M_{2}\right)$, and shallow-water overtide $\left(M_{4}\right.$ and $\left.M_{6}\right)$ peaks are shown.

to forcing by the atmosphere. Current meters provided temporal coverage of a statistically sufficient number of passages of atmospheric pressure systems to attempt a separation of wind-driven flows from the gravitational circulation [Wang and Elliott, 1978; Wang, 1979; Pritchard and Rives, 1979; Pritchard and Vieira, 1984; Vieira, 1985, 1986]. The upper layer 
of the estuary responds rapidly to an axial wind stress. This motion sets up a surface slope, which drives a flow in the opposite direction in the lower layer, but with a substantial lag required for the setup and communication of the pressure gradient (governed by the shallowwater wave speed). Over the middle reaches of the Bay, this lag approaches 18-24 hrs, and can be seen in the overlaid current records from upper and lower layers shown in Figure 7. The response to this pressure gradient appears to occur first near the bottom and then progress upward. Vieira [1986] and Pritchard and Vieira [1984] interpret this upward propagation as a gradually increasing dominance of the barotropic flow over a decreasing wind stress at the surface. However, the details of the physics remain uncertain. Part of the difficulty in deciphering these dynamics is the coupling of this two-layer response to the seiche motion.

The magnitude of the wind response in the upper and lower layers of the Chesapeake Bay appears surprisingly similar in Figure 7 given the disparity in their effective cross-sectional areas. If there were no friction and the lower-layer transport balanced the upper-layer transport, then a proportionally stronger flow might be expected in the sharply narrower lower layer (see Figures 1 and 2). However, bottom and side friction limit this stronger flow to a relatively narrow jet located immediately below the pycnocline. The single-point current measurement shown in Figure 7 is taken toward the side of the central channel, away from the velocity maximum. An additional reason for the larger-than-expected velocity in the upper layer, given it's significantly greater width, is that this directly wind-driven flow is also part of the initial seiche response. The flow acts to fill or empty the quarter-wave seiche, and therefore the upper and lower-layer transports would not expected to be balanced unless averaged over the 2-day seiche period.

Wind-driven flows can dominate all circulations, including the tides, for intervals up to 3 days. Goodrich et al. [1987] show that this response is dependent on the ambient stratification. In turn, with strong wind events creating particle transport distances greater than $100 \mathrm{~km}$, and with longitudinal gradients in salt, wind can significant alter the density structure via advection alone.

Recent work indicates that in both fjords [Farmer and Freeland, 1983] and coastal plain estuaries [Goodrich et al., 1987], wind mixing can be of the same order as that produced by tidal interaction with the bottom topography. A particularly dramatic example of wind mixing in the Chesapeake Bay is described by Goodrich et al. [1987], where cold-air outbreaks destratified the Bay. Large velocity shears preceded destratification events, suggesting a dynamic instability mechanism at the pycnocline for the primary mixing process.

\section{Estuarine Circulation}

The Chesapeake Bay has served as the primary laboratory for development of ideas on the circulation of estuaries [Beardsley and Boicourt, 1981]. Pritchard [1954,1956,1967], using the James River Study as the foundation, describes what is now referred to as the classical estuarine circulation, with fresh water moving seaward over salt water moving toward the head of the estuary. The unique aspect of a partially mixed estuarine flow such as in the Chesapeake Bay is that mixing energy contributes to an amplification of the two-layer flow in the seaward direction. In contrast to salt wedge estuaries, where mixing is preferentially unidirectional from the lower layer to the upper layer, mixing in a partially mixed estuary is directed both ways. Not only are water properties altered in both layers during the travel along the axis of the Bay, but the transport within each layer increases in the seaward direction. Although direct measurements of transport within these layers has proved 

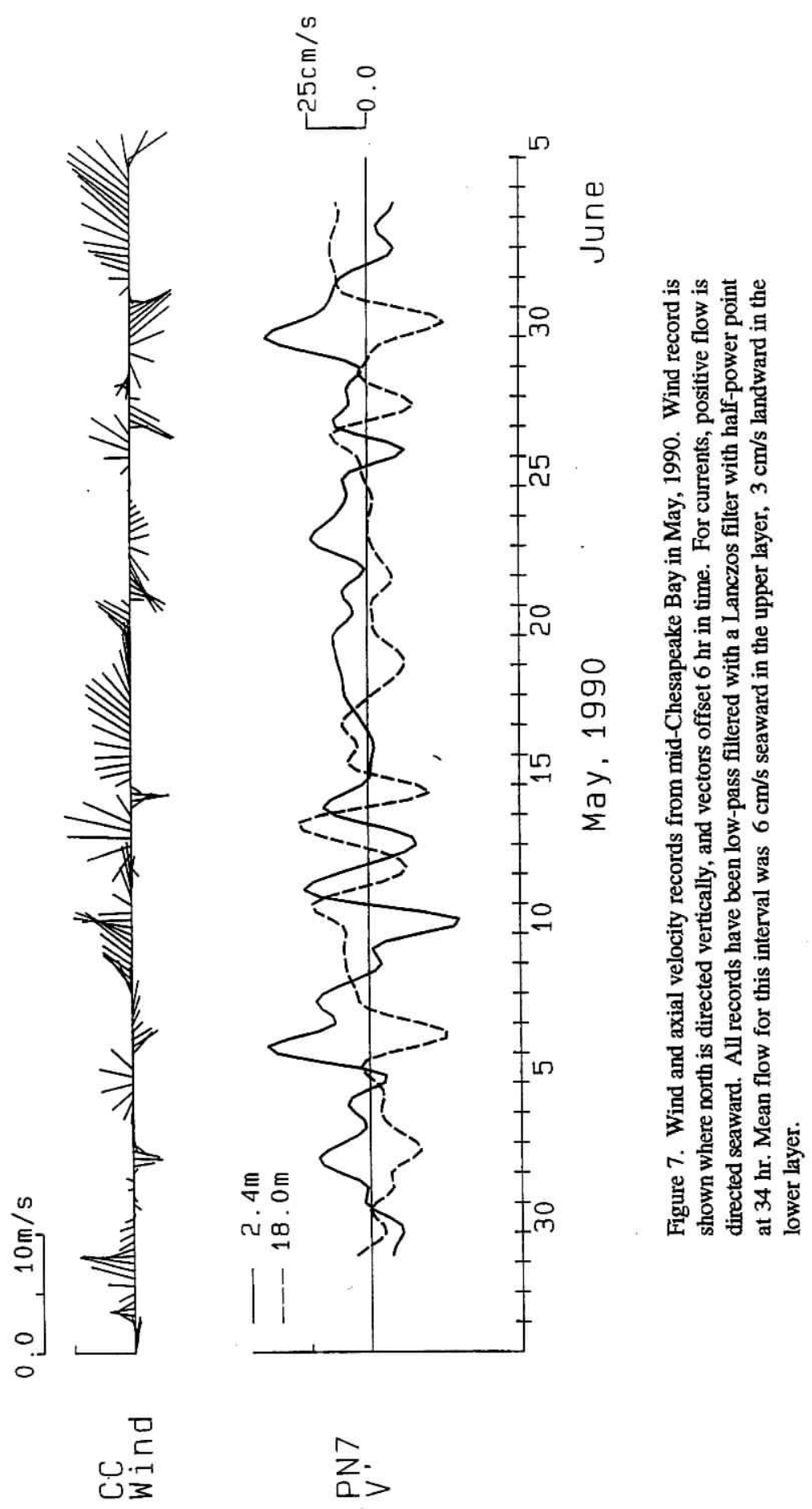
difficult [Boicourt, 1973; Stone, 1994; Jay et al. 1997], estimates of Chesapeake Bay discharge reach 4-6 times the entering river flow. The gravitational circulation in Chesapeake Bay is typically $7-15 \mathrm{~cm} \mathrm{~s}^{-1}$, significantly weaker than tidal velocities, and easily outmatched by the wind-driven flow. Nonetheless, this circulation is unidirectional and comparatively steady, and constitutes the primary transport mechanism for Chesapeake Bay.

Now that the era of research on wind-driven estuarine variability has had a two-decade run, interest has been rekindled in gravitational circulation, in an attempt to decipher its elusive physics. The Chesapeake Bay tributaries, with their varied geometry, river inflow, and connection to the main-stem circulation, have provided a rich set of realizations through which to test ideas. We now recognize that the spectral gap, once assumed to separate the gravitational from the atmospherically forced circulation, is uncomfortably narrow, or perhaps nonexistent [Goodrich and Blumberg, 1991]. Whereas the meteorological community can exploit this gap in the analysis of the atmospheric circulation, coastal oceanographers are not afforded this luxury. Despite this disadvantage, descriptions of the higher-frequency variability have improved to the point where these more-energetic components of the flow can be extracted deterministically from the lower-level, slowly varying gravitational flow.

A schematic diagram of the superposition of circulation components active in the main stem of Chesapeake Bay is shown in Figure 8. The tides and the oscillatory quarter-wave seiche are barotropic flows with frictional falloffs to the floor of the estuary, while the gravitational circulation and wind-driven flow are, in the main, two-layer motions. A decomposition of a typical current-meter record from the middle reaches of the Bay is shown in Figure 9. Tidal currents, reflecting the typically mixed tides caused by the virtual semidiurnal amphidrome located west of the mid-Bay region, are extracted from the continuum via band-pass filtering. As can be seen from an inspection of the filtered records in Figure 7, the amplitude of the quarter-wave seiche can vary significantly, from barely detectable to active during strong or fluctuating wind forcing, as in the interval 2-10 May, 1990.

In comparison to these energetic and often non-stationary motions, the residual current in this lower-layer example is weak, of order $3 \mathrm{~cm} \mathrm{~s}^{-1}$. Even in the core of the landward jet below the pycnocline, where residual velocities are typically $10-15 \mathrm{~cm} \mathrm{~s}^{-1}$, these gravitational currents can easily be dominated by wind-driven motions. Standard time-series analytical tools have not yet been successful in achieving a separation of the gravitational flow with low signal-to-noise ratio and minimal spectral gap, the extraction of this lower-level flow from the continuum via modeling shows considerable promise.

\section{Plumes and Coastal Currents}

Upon leaving Chesapeake Bay, the buoyant fresher water discharged by the upper layer of the estuary spreads and undergoes a broad anticyclonic turn. In the absence of wind or opposing ambient flow, this rotational turn eventually extends toward the coast, where the plume forms as a narrow, high-velocity coastal current flowing southward toward Cape Hatteras [Boicourt, 1980; Chao and Boicourt, 1986]. Upwelling-favorable winds oppose the turn of the plume, and if sufficiently strong, shut down the coastal current. Conversely, downwelling-favorable winds act to confine the turning region close to the coast and to accelerate the far-field coastal current [Chao, 1987]. An important consequence of the rotational asymmetry of the turning region is that the flood-tidal flow following ebb tide 


\section{Component Decomposition}

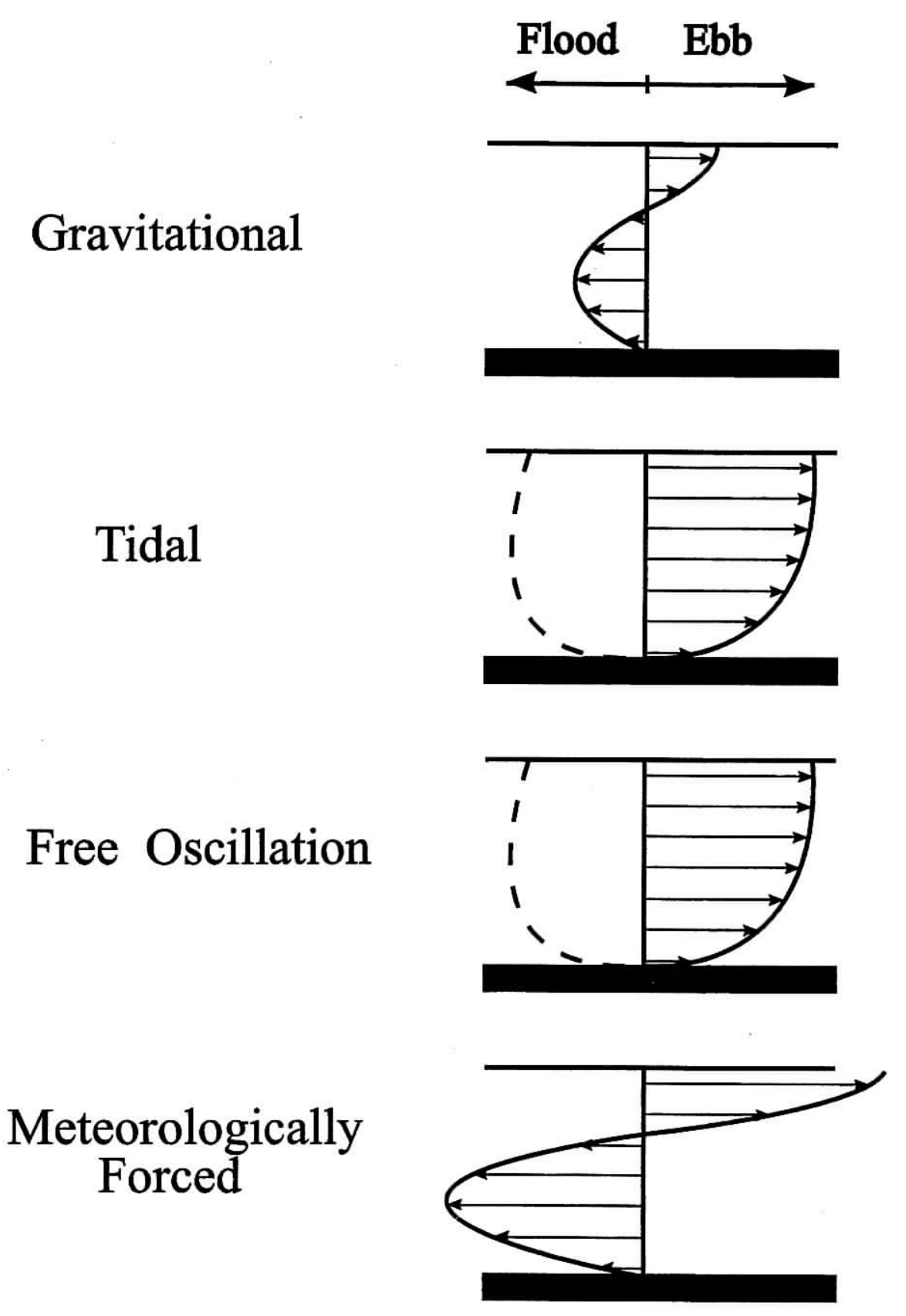

Figure 8. Schematic diagram of circulation components for Chesapeake Bay. 


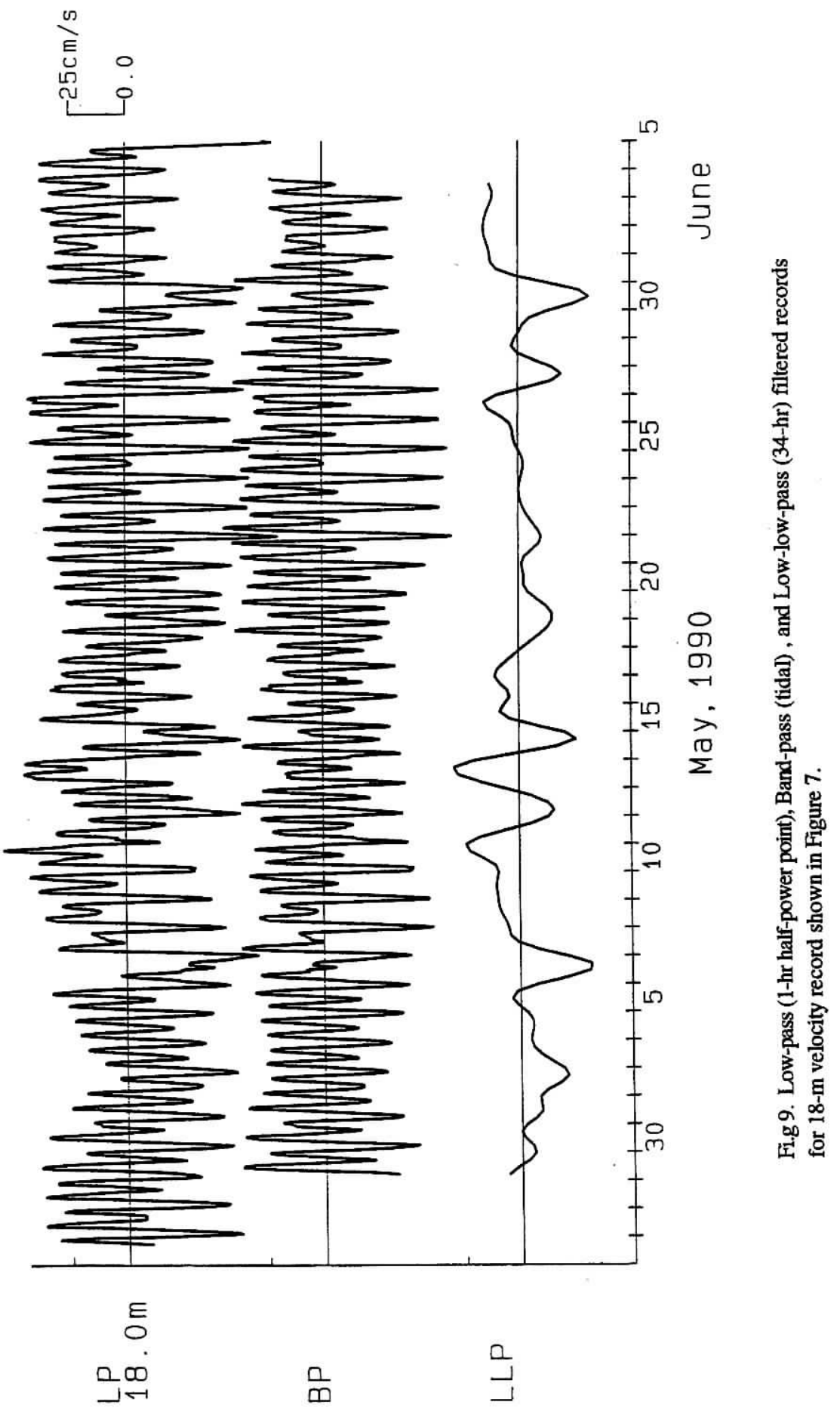


returns far less plume water to the Bay than would the symmetrical spread of low-salinity water in the nonrotating case.

Within the main stem of the Chesapeake Bay, the addition of fresh water from tributary rivers along the western shore has long been understood to either augment the lateral salinity gradient set up by the rotation of the earth or to be the primary cause of the gradient. Recently, observations indicate that, over the lower Bay, where the width of the Bay exceeds the internal Rossby radius, the western shore rivers can produce both plumes and coastal currents. The Potomac River, as the next largest contributor of fresh water after the Susquehanna River, produces the most noticeable plume, with an associated lateral front in the turning region, and a far-field coastal current. Subsequent fresh-water contributions from the Rappahannock, York, and James Rivers merge into this flow, the summation producing a marked lateral gradient by the entrance to the Bay.

\section{Topographic Effects}

Although the stratification of Chesapeake Bay waters acts to decouple the upper-layer motions from the influence of bottom topography, the Bay is so shallow that these flows are seldom isolated from its effects. Hydraulic controls were recently found to be active, both in the main stem [Chao and Paluszkiewicz, 1991] and in the tributaries [Sanford and Boicourt, 1990] of Chesapeake Bay. Hydraulic controls serve not only to arrest the propagation of gravity-current transients, but also to constrict the steady-state gravitational circulation.

The ability of topography to profoundly affect estuarine flows is not restricted to direct influences such as hydraulic control at sills and constrictions or by trapping in lateral embayments. Curves in channels can create secondary flows [Dyer, 1973, 1977; Boicourt, 1983], analogous to those observed in river bends. In addition, residual currents arise from interaction of oscillatory motion of the tides with the bottom topography. The Stokes drift associated with the incoming tidal wave creates a longitudinal slope in the surface elevation, which in turn drives an Eulerian seaward flow [Pritchard, 1980]. Such drifts induced by progressive long waves have been incorporated into the analysis of estuarine flows for some time. However, for estuaries with large tidal excursions and large topographic variability, Lagrangian residual flows generated by horizontal gradients in tidal velocities are now recognized to contribute to the transport. Ianiello [1977], Zimmerman [1978, 1979], and Wilson et al. [1986] describe rectification of oscillatory tidal currents by a spatially variable bottom topography. These rectified currents are not only a transport modification to the mean Eulerian velocity field, but are also the source of "residual vorticity" [Zimmerman, 1978] modifying both the dynamics and mixing processes. Although these residuals are not expected to be of first-order importance over the central portion of the main stem of Chesapeake Bay, they become so near headlands and in shallow tributaries.

Fronts, ubiquitous features of the estuarine environment, are often generated by processes set up by interactions with the bottom topography. Frictionally driven secondary flows can produce axial convergences in smaller tributaries [Simpson and Nunes, 1981; Simpson and Turrell, 1986]. Similar longitudinal fronts have been observed in the Chesapeake Bay and its tributaries at lateral breaks in the channel topography or in high shear zones [Huzzey and Brubaker, 1988]. In these cases, the convergences are created by frictionally induced differential advection in the presence of a longitudinal density gradient. 


\section{Ecological Implications}

Although it is often held up as the archetypical estuary, Chesapeake Bay is unusually long. The primary ecological consequence of this $300-\mathrm{km}$ length is that transport times are long compared to most of the important biological time scales. As water flows seaward from the mouths of entering rivers, there is time for introduced nutrients to support a phytoplankton bloom, to sink out of the upper layer at the end of the bloom, and to enter the lower layer flow directed toward the head of the estuary. Such a retentive system allows ample time for recycling, or even burial by sedimentation. Such a system is also conducive to the development of oxygen depletion in the lower layers in summer. Furthermore, the two-layer flow regime enables estuarine species to exploit its motion via vertical positioning for recruitment and migration stages of their life cycle [Boicourt, 1988].

The introduction of buoyancy to the estuary via river outflow not only induces the classical estuarine circulation, but it also creates stratification. For summer oxygen depletion in Chesapeake Bay, the primary role of stratification is to suppress vertical exchange. Stratification thereby limits reaeration following the remineralization of organic matter sinking from the spring bloom in the upper layers. Officer et al. [1984] found an increasing trend in the volume of anoxic waters in the interval 1950-1980 and ascribed it to the observed increase in nutrient loading. Spring runoff can determine summer stratification, despite intervening destratification events, through the buildup of a buoyancy reservoir, which creates a longitudinal gradient in the sectionally-averaged salinity [Boicourt, 1992]. Recent analyses indicate that, if the river-flow related variability is removed from the record, an obvious underlying trend of increasing anoxia emerges.

The two-layer estuarine circulation not only acts to retain nutrients, but can also provide a mechanism to retain or recruit planktonic organisms. Estuarine species can exploit this circulation by vertically migrating and thereby minimizing horizontal transport along the estuarine salinity gradient. Tyler and Seliger [1978] describe the role of estuarine circulation in the life history of the dinoflagellate, Prorocentrum, which moves from an overwintering population in the southern Chesapeake Bay to summer bloom formation in the northern Bay. The blue crab, Callinectes sapidus, disperses its eggs and larvae to the continental shelf for development. Subsequently, the late-stage larvae exploit the estuarine circulation to return into the Bay and into nursery grounds.

Many additional examples of estuarine physical controls of ecological processes can be identified, such as productivity bursts driven by upwelling of nutrient-rich waters, biological responses to destratification and reaeration events, and alteration of predator-prey relationships by motion and stratification. Convergence zones, such as turbidity maxima, plume fronts, and tidal fronts, has recently received attention for their role in regulation of production and recruitment. However, the most important processes influenced by the motion and structure of Chesapeake Bay waters are the transport and dispersion of nutrients, their uptake in the spring phytoplankton bloom, and the ultimate decomposition of this organic matter. The most important unknown remains the details of the modes and mechanisms of exchange in the vertical dimension: the migration and sinking of particles, and the mixing of upper- and lower-layer waters. Central to this understanding is the quantitative relationship of stratification to the buoyancy and mixing processes working to create and destroy this regulator of vertical exchange. 


\section{The Northern Adriatic Sea}

\section{Oceanographic Setting}

The Adriatic Sea is a long $(800 \mathrm{~km})$, narrow $(200 \mathrm{~km})$ epicontinental basin surrounded by the Dinaric, Alpine and Apennine mountain chains. Its present morphology is the result of both tectonic and sedimentation processes. Quatemary sediments, supplied chiefly by the Po River, prevail in the northern part [Brambati, 1990]. The Northern Adriatic is the shallowest part of the Adriatic Sea. Its southern boundary is open and topographically not clearly defined. This smooth, semi-enclosed shelf slopes down gently in the southeast direction until near the $100 \mathrm{~m}$ isobath, after which topography changes more abruptly towards the Jabuka Pit (Figure 10). Hypsographic curves for the region north of the Pula-Rimini line (Figure 11) reflect this gradual deepening.

The Alpine range and Mediterranean Sea have a major influence on the meteorological conditions over the Northern Adriatic. The Alps represent an important obstacle to the cold air from northern Europe, whereas the destabilizing effect of the Mediterranean facilitates cyclogenesis in the Gulf of Genoa. In winter, when the pressure gradient between the quasi-stationary Eurasian anticyclone and low-pressure activity-centers over the Mediterranean is sufficiently large, cold and dry air from the north breaks into the Northern Adriatic area. These air masses move over the low and narrow passes between Alpine and Dinaric chains, developing severe winds [Furlan, 1977]. This gusty, katabatic wind from the Northeast (called Bora on the westem and bura on eastern side of the Adriatic), blows over the shallow shelf and intensifies evaporation and cooling fluxes. These fluxes are sufficient to produce vertical instability and convection down to the bottom [Hendershott and Rizzoli, 1976]. This dense water formation process takes place in the Northern Adriatic every winter, but its intensity varies interannually, depending on the severity and persistence of meteorological conditions. The spatial heterogeneity of Bora, due to local orographic features, has important consequences for the response of the water [Kuzmić and Orlić, 1987].

Another important winter wind is Sirocco, blowing from the Southeast. There are two types of Sirocco: one associated with a clear sky, termed anticyclonic Sirocco, and the other accompanied by rain, called cyclonic Sirocco [Buljan and Zore-Armanda, 1976]. In summer, dry and invigorating ethesian winds from the Northwest dominate. Although characterized by persistency in strength and direction, their magnitude is weak and often masked by local wind patterns [Makjanić, 1976].

\section{Fresh Water Inflow}

The hydrology of the region is dominated by the Po River. After damming of the Nile, the Po River system became the largest single river discharge to the Mediterranean. Its watershed is large, covering some $72,000 \mathrm{~km}^{2}$, and extending longitudinally across some 680 $\mathrm{km}$ [Milliman et al., 1995]. The Po runoff reaches the Northern Adriatic through an elaborate delta, but three channels (Dritta, Gnocca, and Tolle) carry approximately $60 \%$ of the flow. The average Po discharge is $1,500 \mathrm{~m}^{3} \mathrm{~s}^{-1}$, but it changes within and between years. The flow shows pronounced seasonal variability. The multiannual plot of the flow (Figure 12) clearly exhibits this seasonality: one cluster of maxima appears in spring (due to melting of mountain 


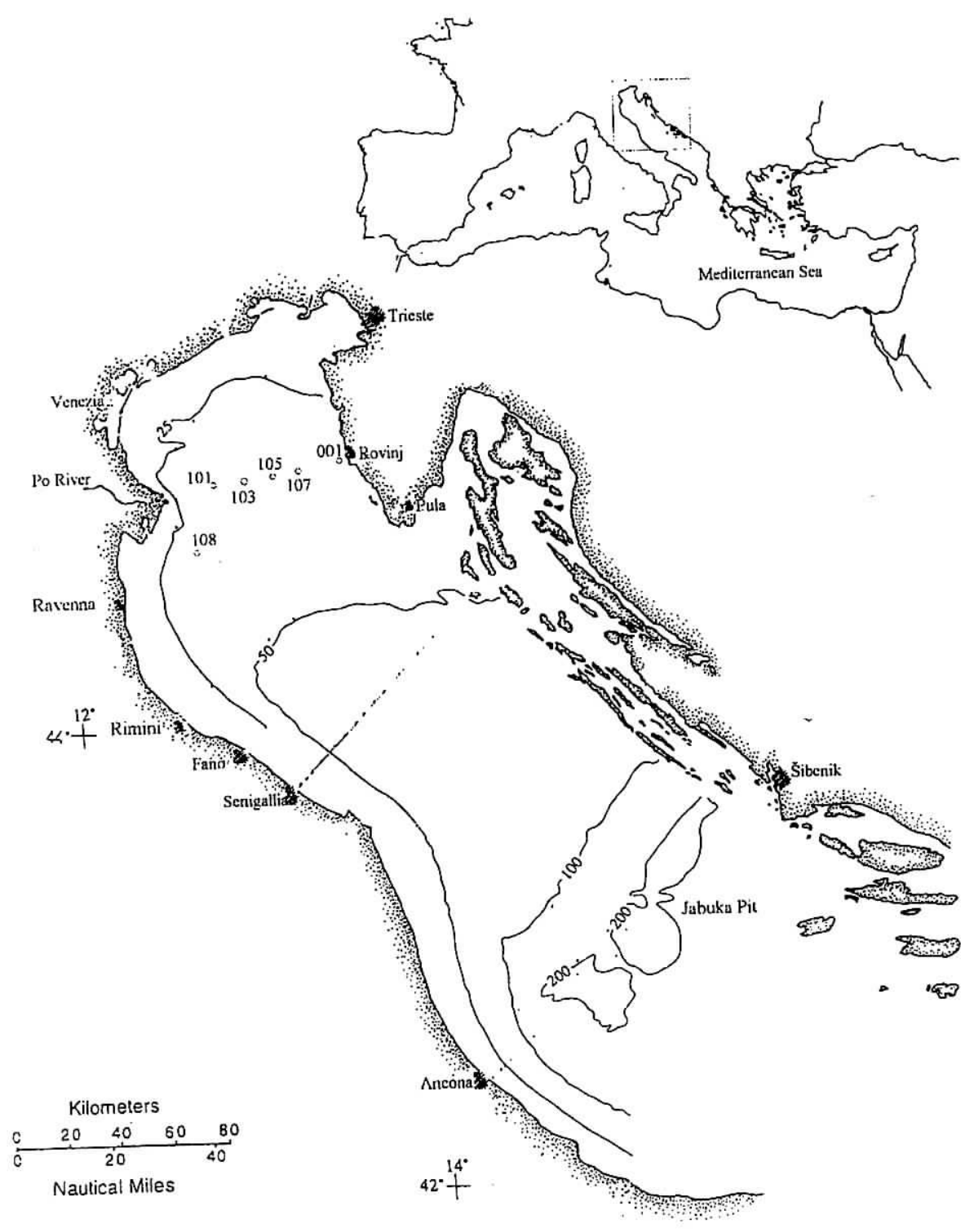

Figure 10. The Northern Adriatic Sea. Also indicated are the Rovinj-Po and Senigallia transects

snow) and another in autumn (due to heavy precipitation). Both winter and summer are seasons of lower runoff. Runoff also exhibits significant interannual variability. This large discharge of water, with its associated load of solutes and particulates, leaves a characteristic fingerprint on the Northern Adriatic density structure and circulation. As numerous studies show [e.g. Franco, 1972], in late autumn and winter the Po discharge hugs 

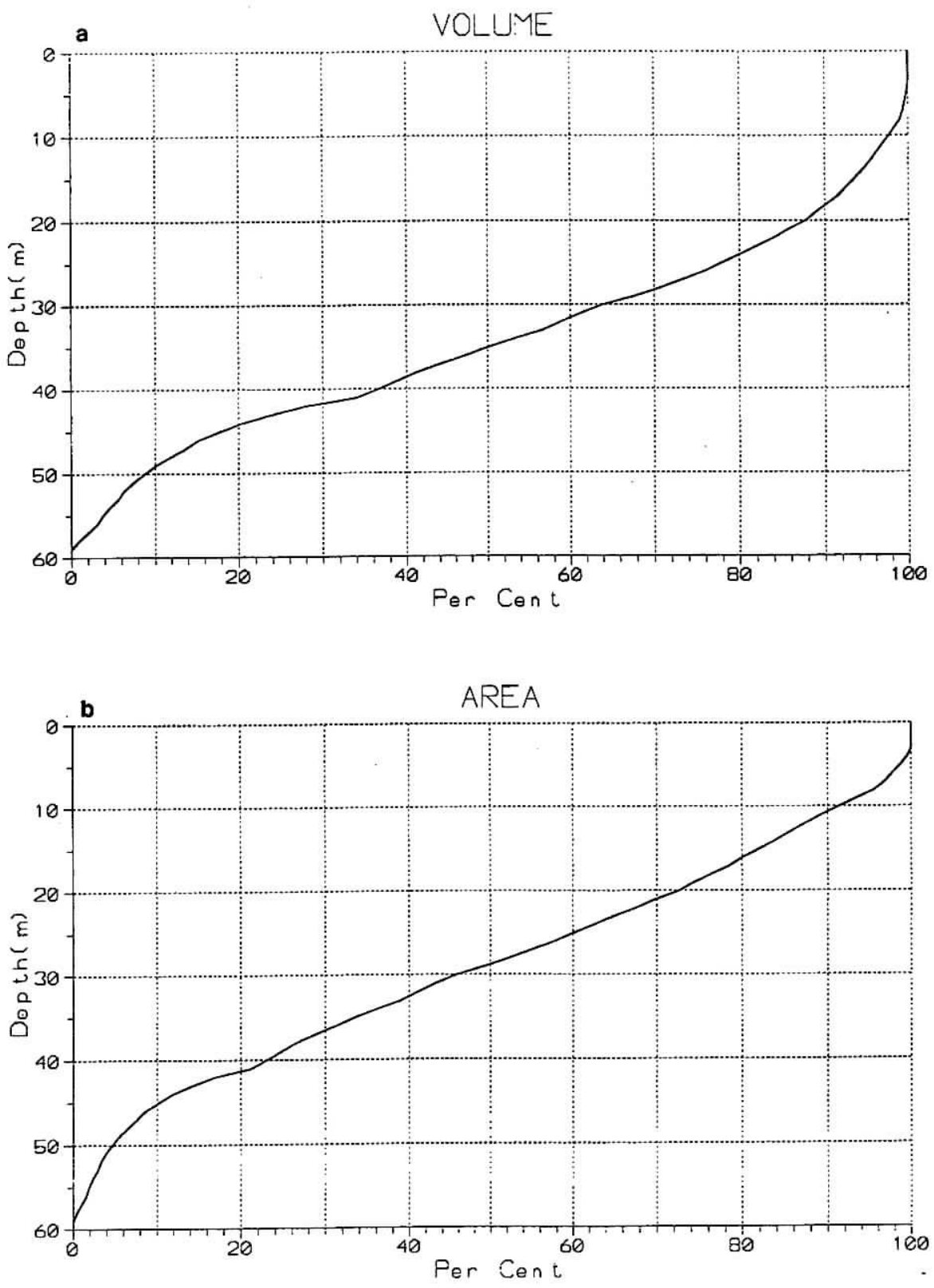

Figure 11. Distribution of the Northern Adriatic volume (a), and area (b) with depth. The curves are drawn for the basin Northwest of the Pula-Fano line (see Figure 10). 


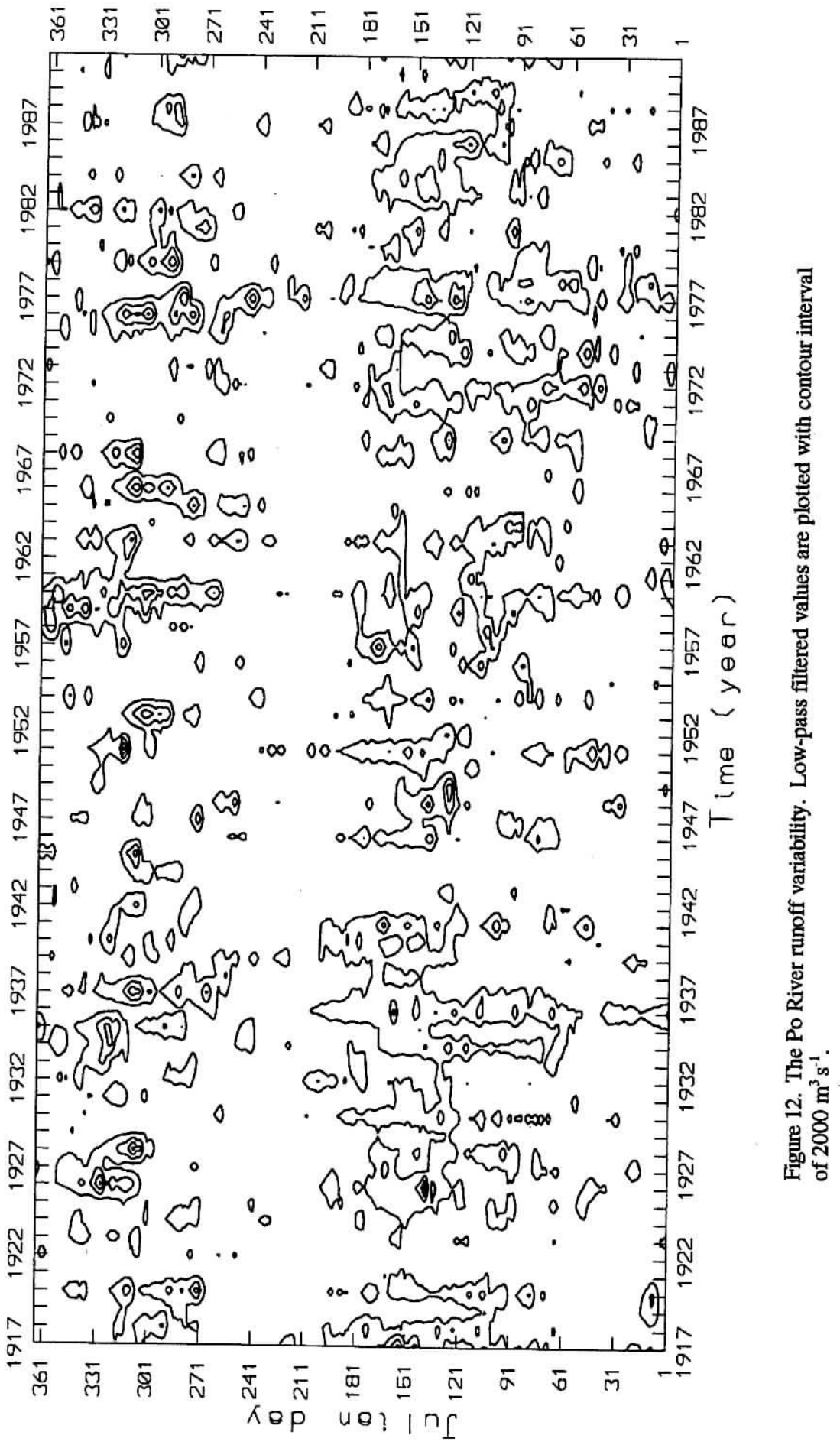


the western coast, forming a coastal boundary layer of lighter water. The remainder of the basin is characterized by a nearly uniform vertical distribution of hydrographic properties. In late spring and summer, the water column is highly stratified, with surface and bottom layers separated by a pronounced pycnocline. Under these conditions, the freshwater discharge is more likely to spread or be wind-forced into the basin interior.

\section{Tides and Free Oscillations}

The Mediterranean tidal signal is weak in general, but in some regions, shallow topography can help produce a harmonic amplitude in excess of $10 \mathrm{~cm} \mathrm{~s}^{-1}$. One such area is the Adriatic Sea, especially in its northern portion. Both empirical analyses [e.g. Polli, 1960] and modeling studies [e.g. Accerboni and Manca, 1973] show that northern Adriatic semidiurnal amplitudes approach $30 \mathrm{~cm}\left(\mathrm{M}_{2}\right.$, Trieste, $\left.27 \mathrm{~cm}\right)$, while diurnal harmonics attain their highest amplitude of the entire Mediterranean $\left(\mathrm{K}_{1}\right.$, Trieste, $\left.18 \mathrm{~cm}\right)$. Semidiurnal constituents show a well-known amphidromic point approximately midway between Sibenik and Ancona. The total signal is of mixed type. Cavallini [1985] is among the few who studied northern Adriatic tidal currents. His calculations of the $\mathbf{M}_{2}$ ellipses indicate their shoreline alignment. Current magnitudes are of $10 \mathrm{~cm} \mathrm{~s}^{-1}$ or less, with major axes an order of magnitude greater than the minor axes. He also observed, both in model and empirical data, changes in the sense of rotation as one moves southward from the shallowest northern part; anticyclonic rotation characterizes the northern region while cyclonic rotation is evident in the southern region. Another recent modeling study indicates that diurnal currents $\left(\mathrm{K}_{1}\right)$, apart from southwest and southeast of Sicily, exceed $5 \mathrm{~cm} \mathrm{~s}^{-1}$ only in the Adriatic [Tsimplis et al., 1995]. Tsimplis et al. demonstrated the crucial roles of both the equilibrium tides and the input of tidal energy from the North Atlantic for the Mediterranean tides. However, while the incoming Atlantic wave dominates the Mediterranean tides up to approximately $1^{\circ} \mathrm{E}$, in the Adriatic the tides are only marginally modified by the forcing at Gibraltar. Compared to combined forcing, forcing by the equilibrium-tide alone does not significantly change the position of the Adriatic $\mathbf{M}_{2}$ amphidrome, while Gibraltar-only forcing produces $\mathbf{M}_{2}$ model amplitudes $20 \mathrm{~cm}$ less than the observed tide in the northern Adriatic. Furthermore, the $K_{1}$ amplitudes are underestimated by more than $14 \mathrm{~cm}$, while $\mathrm{O}_{1}$ phase differences exceed $130^{\circ}$. Apparently, tidal mixing has not received particular attention as a dispersal mechanism in the northern Adriatic. In a rare qualitative effort to address this problem, Grancini and Cescon [1973], tracing nitrate in a nearshore area, found the tidal currents capable of modifying the Po River plume pattern.

In a basin like the Adriatic, a broad spectrum of oscillations is likely to be triggered under various meteorological conditions. Intensive SE winds (Sirocco) and passages of frontal/cyclonic systems incessantly perturb the Adriatic, triggering seiches with periods very close to some diurnal and semidiurnal tidal constituents. The study of barotropic standing waves has been a recurring theme of Adriatic oceanography. Earlier work on the Adriatic seiches has been summarized by Defant [1961], while more recent contributions have been addressed by Buljan and Zore-Armanda [1976] and Franco et al. [1982]. Time-series filtering [e.g. Manca et al., 1974], spectral analysis [e.g. Godin and Trotti, 1975], as well as analytical [e.g. Sguazzero et al., 1972] and numerical models [Schwab and Rao, 1983] have all been employed in the analyses. Theoretical as well as empirical investigations have as a rule 
considered the basin proper, establishing over the years the Adriatic gravest-mode period close to 22 hours, and its first harmonic at about 11 hours (the most often reported value of $10.8 \mathrm{~h}$ ). Recently Cerovecki et al. [1997] undertook empirical and modeling study of the damping and energetics of the $21.2 \mathrm{~h}$ Adriatic seiche. They found the free decay time to be $3.2 \pm 0.5$ days, and cross-Adriatic wind to be of comparable importance to along-Adriatic ones in affecting the decay.

Wind episodes or rapid passages of atmospheric disturbances can also trigger inertial oscillations. Those oscillations have a pronounced seasonal variability, closely related to the degree of stratification. Their presence in the northern Adriatic has been repeatedly demonstrated [Accerboni et al., 1979; Accerboni et al., 1981; Michelato, 1983]. Orlić [1987] analyzed wind, current and hydrographic data taken during three summer seasons at four northern Adriatic stations. His analysis shows partition of energy between surface and bottom layers as a function of thermocline depth, and clockwise current vector rotation with opposing phase across the thermocline. At two stations close to the longitudinal boundary the inertial currents accounted for about $10 \%$ of the total variance, whereas further offshore the inertial contribution went up to 20-30\%. Krajcar and Orlić [1995] have shown that amplitudes of inertial currents are at maximum in summer (about $10 \mathrm{~cm} \mathrm{~s}^{-1}$ in the surface layer), staying within the noise level throughout the winter. They found the ratio of inertial-current amplitudes observed above and below the pycnocline to be controlled by the pycnocline depth. Oscillations were damped, with decay times between 20 and 80 hours, the maximum occurring in summer.

\section{General Circulation Overview}

General Adriatic circulation studies have a relative long history, dating back to late 19th century. In the last twenty years there have been several review efforts to consolidate current understanding [Buljan and Zore-Armanda, 1976; Franco et al., 1982; Orlić et al., 1992]. Wolf and Luksch [1887] produced one of the first charts of the Adriatic surface circulation in summer. Although subjective and somewhat qualitative, their chart contained at least two features that survived the scrutiny of later studies: cyclonic orientation of the mean circulation and the existence of smaller, again cyclonic cells. In a seminal paper, Zore [1956] calculated geopotential topographies relative to 50,100 and $200 \mathrm{dbar}$ surfaces. Her geopotential topographies suggest a distinct seasonal variability in the circulation pattern: pronounced surface currents along the eastern coast in winter, and along the western coast in summer. In her analyses, the winter inflow was primarily compensated by an outflow in the bottom layer, while more pronounced summer surface outflow was balanced by an increased inflow at the intermediate layer.

The idea of the northern cyclonic gyre can be traced back to Feruglio [1920] and his analysis of the "Ciclope" drift bottle releases. More recently, Mosetti and Lavenia [1969] calculated dynamic heights relative to $20 \mathrm{dbar}$ level. Their calculations indicated the existence of a relatively stable cyclonic circulation northeast of the Po River mouth. This finding is echoed in the work of Franco [1970]. Some supportive information can be found in sediment studies as well. Pigorini [1968], for example, invokes this cyclonic circulation to explain a tongue of mud and sandy mud extending from the Po River into the Northern Adriatic basin. Zore-Armanda and Vučak [1984] looked at current meter data collected at oil-drilling platforms at 10 locations in the Northern Adriatic, unevenly covering different seasons (from 
1971 to 1982). Their analysis of surface and bottom residual current vectors reinforces existing understanding of the mean circulation: northward flow along the eastern and southward flow along the western coast.

Limited modeling efforts have also addressed some dynamical aspects of the winter and summer circulation in the Northern Adriatic. Hendershott and Rizzoli [1976] found the wintertime sensible and latent heat fluxes, when combined with fluvial outflow, was capable of producing horizontal density gradients sufficiently strong to drive a cyclonic flow of the order of $0.1 \mathrm{~Sv}$. Malanotte-Rizzoli and Bergamasco [1983] were primarily concerned with the situation offshore the Emilia-Romagna region (downstream of the Po delta) and the relationship of Po River to the observed eutrophication. Their numerical simulations seem to suggest the dominance of the thermohaline over wind-driven circulation while reinforcing the notion of occasional flow reversals (small circulation cells) off the Emilia-Romagna coast.

Some aspects of the Northern Adriatic circulation can be clarified by looking at the circulation as determined from the observed density field [Hopkins, 1996; Hopkins et al, 1998]. Figure 13 shows the contours of the adjusted steric heights for the same two observational periods for which the fresh water content is shown in Figure 14. The geostrophic surface flow is parallel to these contours and is inversely proportional to the distance between them. Any frictional wind contributions occurring at the time of observation would not be reflected in these distributions; in both cases shown there were no significant wind events. The tendency of the sea level contours to follow the bathymetry of the Italian coast is a characteristic of a geostrophic boundary current. Similarly, the contours are coincident with the freshwater content because the lower density waters have a greater steric volume. The Western Adriatic Current (WAC) primarily originates off the Po delta; in the region off Ravenna, it tends to be sluggish as fresh water accumulates there. South of Rimini, the flow tends to narrow and become better defined by a strong sea level gradient. The cross-sectional velocity structure and transports for the Senegallia transect are shown in Figure 15, as calculated by the steric-height method [Hopkins, 1996b].

The topography of the adjusted sea levels (Figure 13) differs considerably between the summer and winter seasons. During the fall-winter transition, the shallower water columns to the north cool more quickly and become denser than the water columns in the Middle Adriatic, which are underlain by warmer waters. This effect causes a considerable sea-level drop to the north and the associated pressure gradient is fairly linear, creating a geostrophic convergence against the eastern boundary, which in turn drives the northward flow on the eastern side [Hopkins et al., 1998]. This flow together with the southward coastal flow to the west provides a complete cyclonic circulation for the northern basin, which has been reported to prevail [Zore-Armanda, 1963; Artegiani et al., 1997]. In contrast, sea level is higher to the north in summer, and the gradient is no longer linear. Here, a smaller-scaled structure occurs, giving rise to a sequence of relative highs and lows along the eastern side. Again, these cells are not closed on the eastern side due to lack of data. The general effect, however, is that the path of the inflowing water meanders northward mostly in the center of the basin, rather than along the Croatian coast. Furthermore, the flat sea-level topography in the very north $(\sim 18$ $\mathrm{cm}$ ) precludes significant flushing of the region (Figure 13).

A sea-level trough just west of the center of the basin tends to prevail (Figure 13). The winter production and spreading of dense water favors the western side, mostly due to the Coriolis force, but also due to the westward convergence of the bottom layer. Consequently, even though most of the winter's dense water production moves out of the Northern Adriatic 


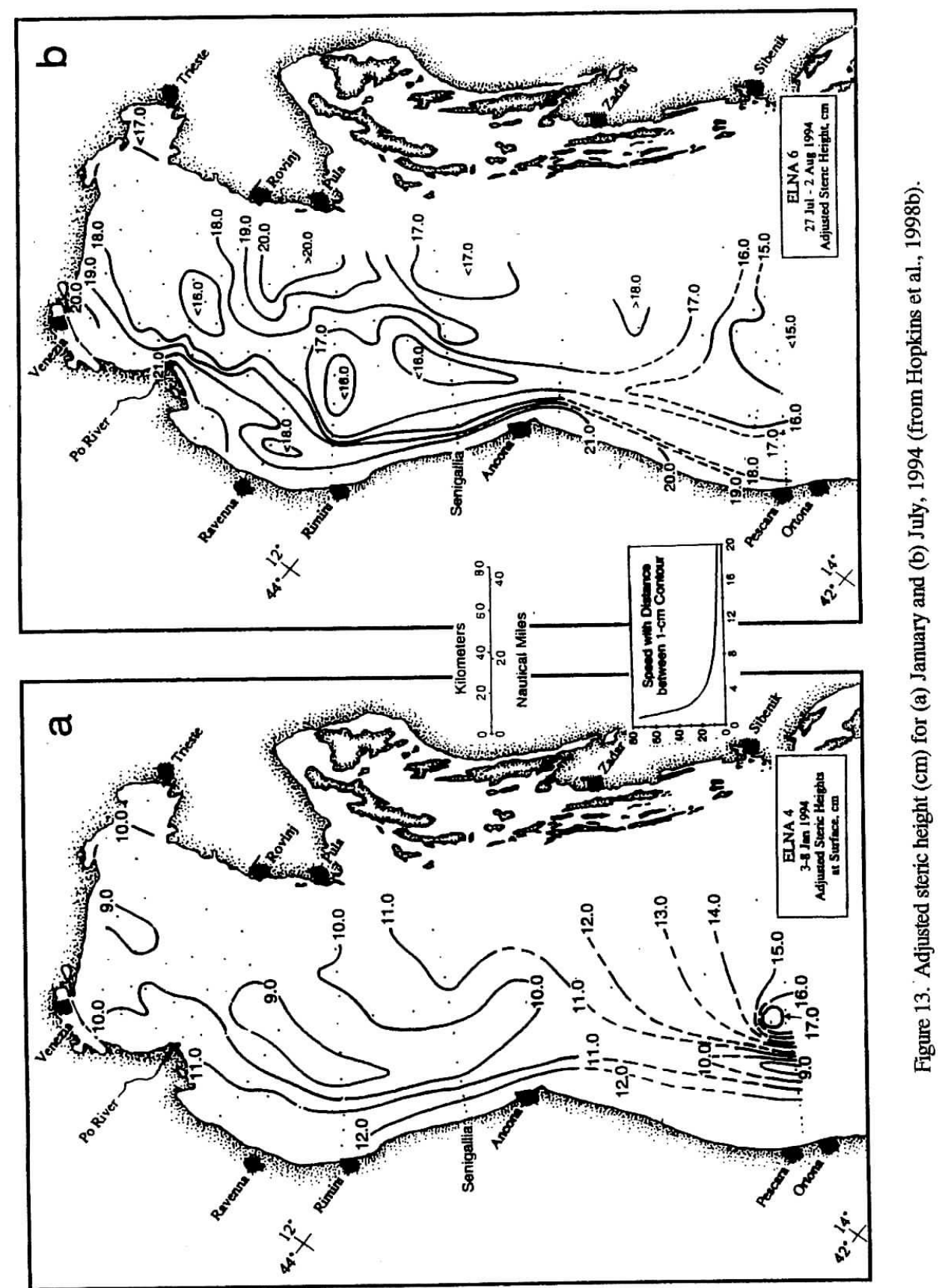




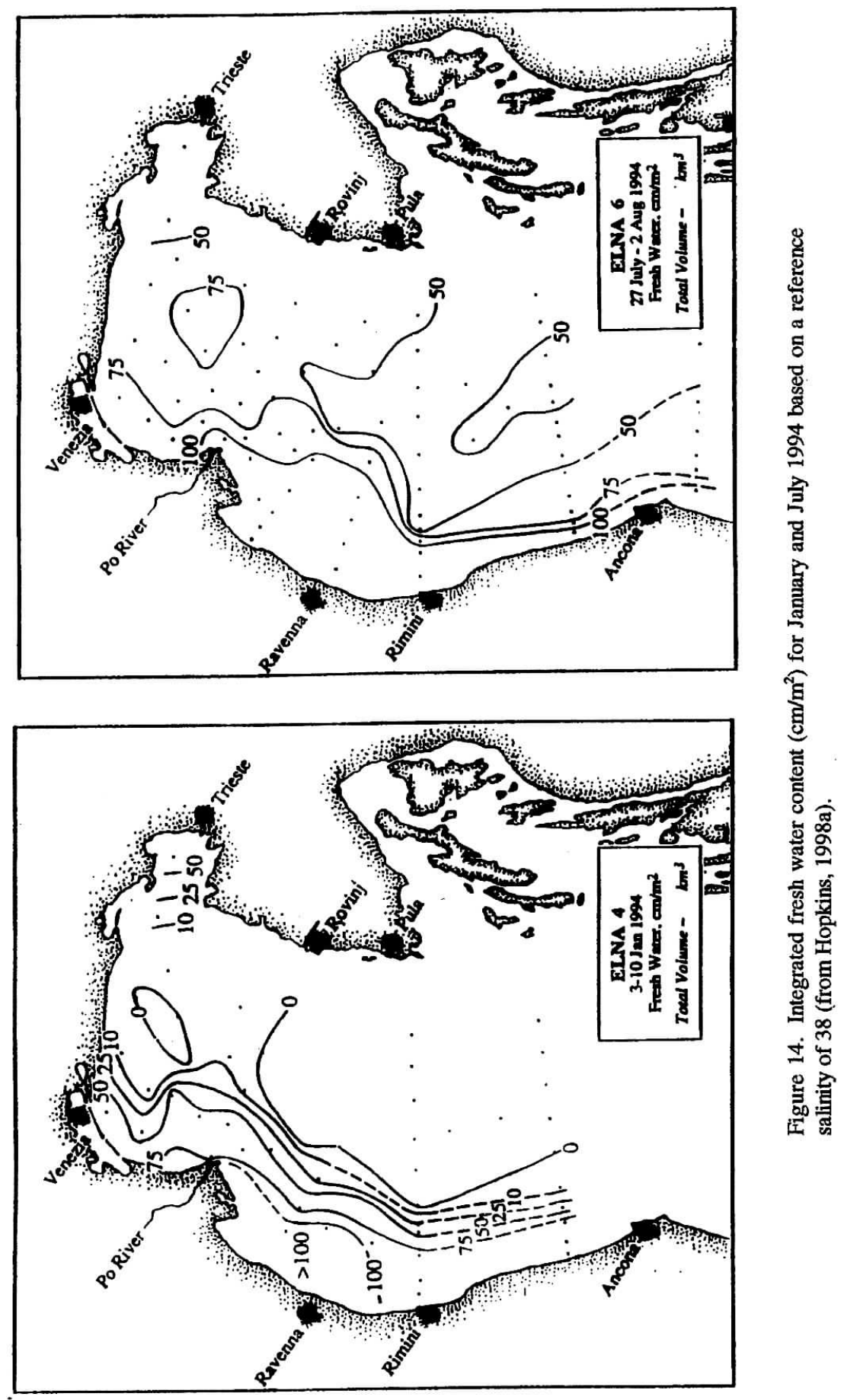




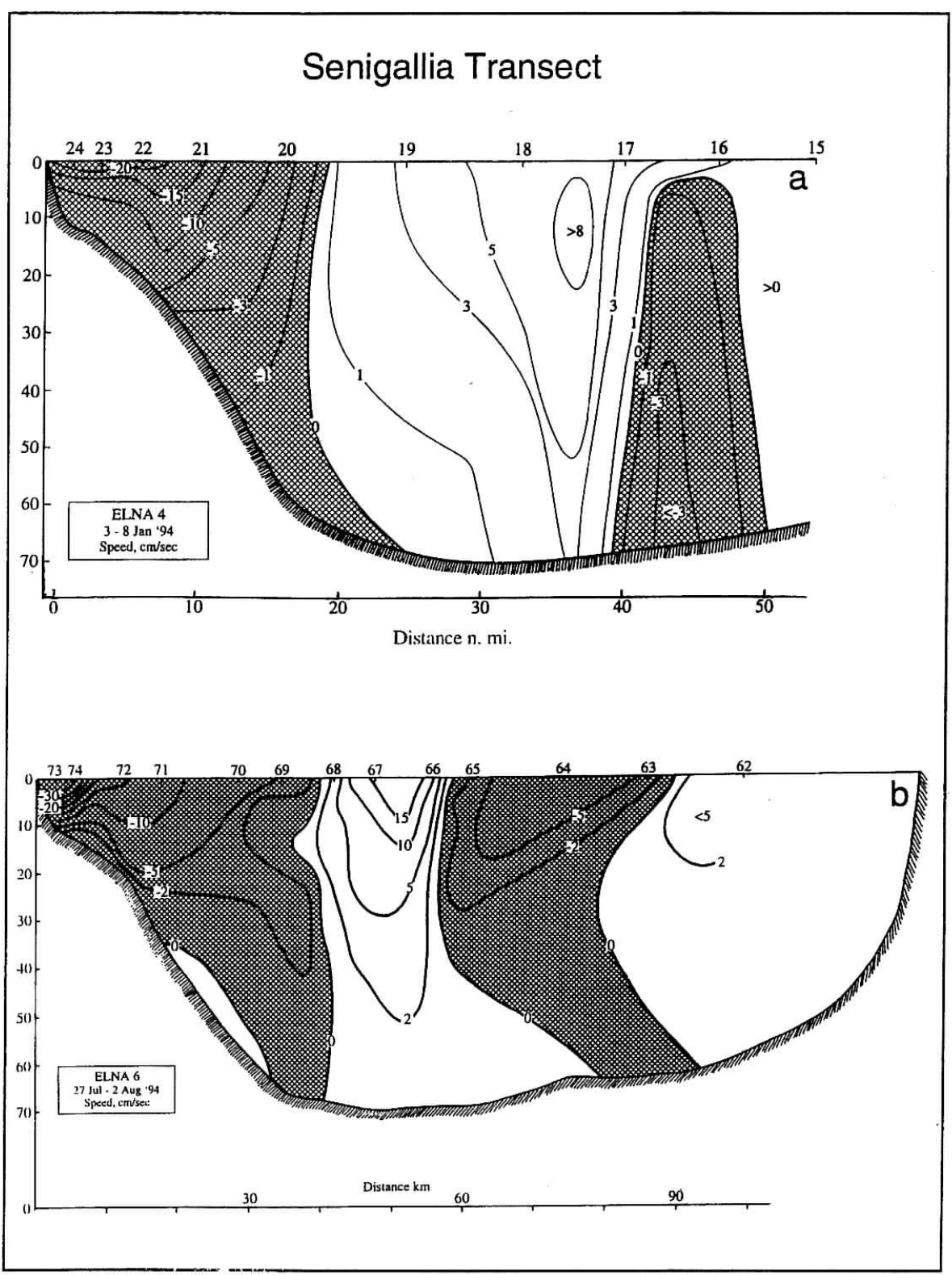

Figure 15a. Geostrophic velocity normal to the Senegallia transect for January and July, 1994 (from Hopkins, 1998b).

by summer, a significant accumulation of dense water still persists. This dense water distribution influences the adjusted sea level in the form of a low pressure trough, which in summer often results in smaller-scaled cyclonic features somewhat analogous to the smaller anticyclonic gyres to the east. This scale cascade tends to retard the advective export of the 


\section{Garibaldi Transect}
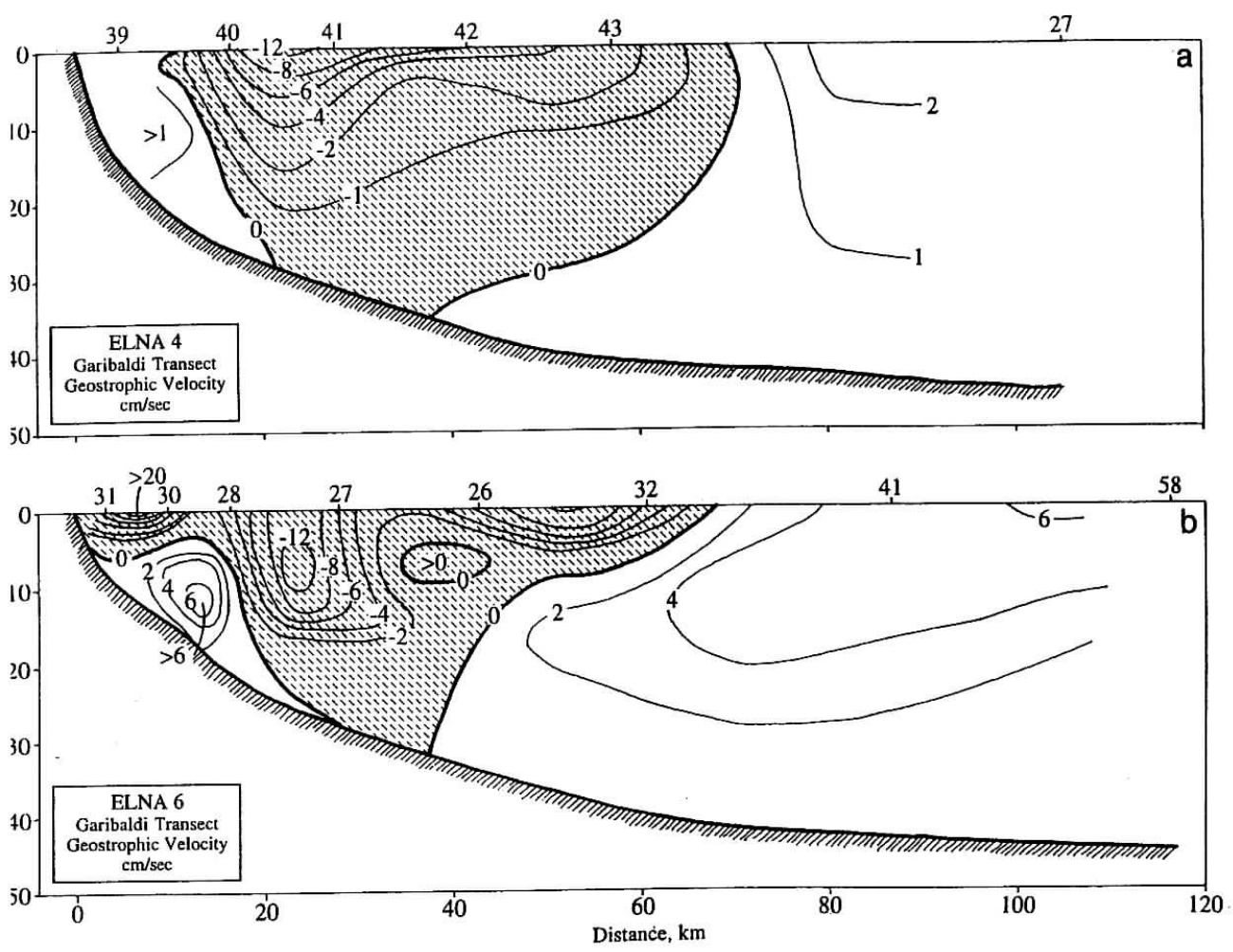

Figure 15b. Geostrophic velocity normal to the Garibaldi transect for January and July, 1994 (from Hopkins et al., 1998b)

western bottom layer and therefore enhances the retention of its waterborne properties and increases the probability of local sedimentation.

\section{Wind circulation}

Mean wind fields over the Adriatic are weak [Markgraf, 1961], but episodes of Bora and Sirocco can significantly affect the Adriatic flow field [Kuzmić and Orlić, 1987; Kuzmić et al., 1988]. The mountainous nature of the land surrounding the Adriatic has a profound influence on the dominant Adriatic winter winds: low and narrow passes in the hinterland impose spatial heterogeneity (curl) on Bora, whereas the Dinaric and Apenninian chains tend to align Sirocco along the Adriatic longitudinal axis. The two winds often appear together-Bora at the north and Sirocco at the south. They can also follow each other--Sirocco blowing while a cyclonic disturbance approaches the Adriatic, Bora when the low leaves the area [Makjanić, 1976, 1978]. The frequency and strength of these winds play an important role in 
determining the water-mass structure and circulation of the Northern Adriatic by either accelerating or retarding the pre-existing thermohaline circulation. In winter, barotropic conditions, Bora can provoke a direct and prompt response throughout the shallow Northern Adriatic water column (Figure 16a). The short time lag (of the sea behind Bora) observed in the time series is also obtained by frequency analysis [Kuzmić and Orlić, 1987]. The analysis of Stravisi [1987] suggests a falling trend in the annual duration of Bora, and the opposite one in southerly winds $(0.28$ days per year for Bora, and 0.26 days per year for southerly winds-Figure 16b).

Apart from being the primary meteorological condition for the dense water formation in the Adriatic during winter, the Bora as a northerly wind strongly affects the surface water mass distribution. Northerly winds generate a surface convergence along the western margin; a strong Bora can, on the order of several days, transport the entire surface layer to the west. However, both empirical and modeling evidence [Kuzmić and Orlić, 1987; Orlić et al., 1994] show that the Bora wind, due to orographic control of the horizontal shear, induces a complex, spatially heterogeneous response. The current field is dominated by this wind-curl effect, exhibiting a string of cyclonic and anticyclonic cells formed around the lows and highs in the sea level height (Figure 17a,b). It is worth noticing that the lower part of the northernmost cyclonic cell advects the Po-affected waters toward the eastern coast. The piling up of water along the western coast generally augments the sea-level slope driving the Western Adriatic Current; the Bora-induced circulation is cyclonic, enhancing the outflow along the western coast, with compensating inflow on the eastern side. The flushing potential of this flow is compromised by the above described return flow. The fact that Bora is predominantly a winter wind further diminishes its effectiveness in reducing the summer residence times of the surface layer.

The response of the Adriatic to Sirocco is somewhat the opposite to Bora. It piles up the water in the Northern Adriatic (Figure 17c,d), creating a surface divergence to the west. Along the Italian coast this creates upwelling favorable conditions opposing the downwelling dynamics of the pre-existing Western Adriatic Current. According to recent numerical modeling results [Orlić et al., 1994] the Sirocco-driven currents are controlled by two competing mechanisms: lateral shearing and vorticity in the Sirocco wind field tend to induce a cyclonic circulation, whereas lateral bottom slope induces downwind flow along both coasts, reinforcing the cyclonic flow along the eastern coast, but stimulating an anticyclonic flow along the western coast [Kuzmić et al., 1988; Orlić et al., 1994]. Limited model-data comparisons support the notion that this interplay of bottom-slope and wind-curl effects may at times reverse the current direction along the western coast. Thus, vertically averaged flow is organized into two longitudinally stretched gyres: a cyclonic gyre occupies a greater part of the basin, while the anticyclonic gyre is constrained to the western coast (Figure 17).

Regardless of its duration and intensity, the effect of Sirocco is to mix the discharge waters into the interior and to retard the flow. In the cross-basin sense, the subsurface waters are transported westward. After a Sirocco, strong gradients in the bottom water are apparent (Figure 18). If the Sirocco continues for more that a day, a general surface convergence causes the sea level to rise from the northern coast. The resulting high pressure blocks further entry of surface flow and creates an area of little net flow, but strong mixing. Recovery from such a Sirocco event is slow because dispersal of freshwater buoyancy is not a reversible process. Thus, the combination of several Sirocco events and several runoff events during the spring can greatly influence the residence time, the strength of the pycnocline and the dispersal of nutrients for the summer season. 


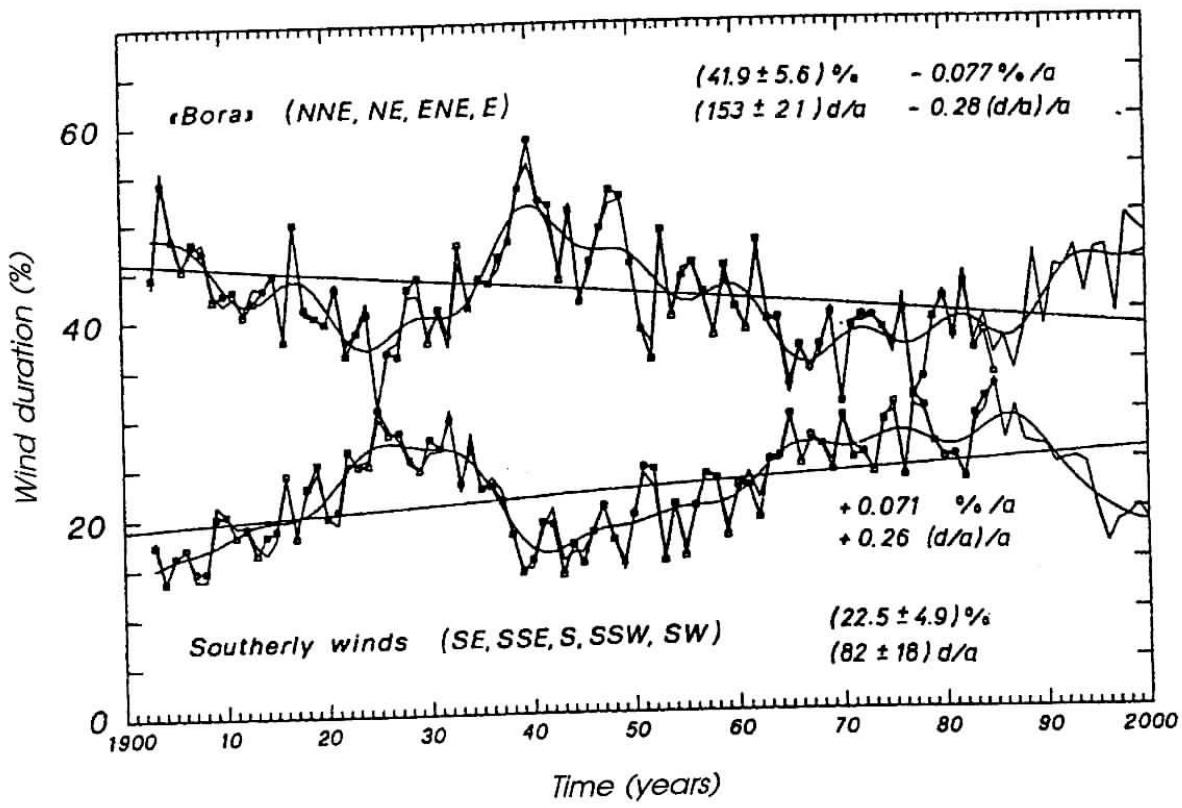

Figure 16. Time series of northeasterly (Bora) and southerly (Sirocco) winds at Triest (19031985 ). Linear trends and long-period(>10 years) harmonics are plotted. The trends are also given numerically, expressed as percentages of the total wind time (\%) and days per year (d/a) together with the means and standard deviations (adopted from Stravisi, 1987).

\section{Thermohaline circulation}

Thermohaline circulations are defined as positive or negative according to whether the mean internal density is less or greater than that external to the basin [Hopkins, 1978]. These density differences are created by differential buoyancy additions (heating, precipitation, and runoff) or extractions (cooling and evaporation) and they determine the vertical structure of the water-mass exchange with the external basin. Positive thermohaline circulations export lighter surface waters and import subsurface external waters to compensate for the loss of mass. Negative circulations export denser waters at depth and import surface waters in compensation.

The mean runoff of the Po and other rivers on the western side of the Northern Adriatic is $\sim 2500 \mathrm{~m}^{3} \mathrm{~s}^{-1}$, contributing $\sim 80 \mathrm{~km}^{3} \mathrm{yr}^{-1}$ to the Northern Adriatic (which down to the Senegallia transect has a volume of $\sim 740 \mathrm{~km}^{3}$ ). If this flow were in steady state and distributed uniformly throughout the volume, the mean salinity would be $\sim 32.5$. This is definitely not the case. During the years 1993-94 the amount of fresh water retained varied roughly from 10 to $20 \mathrm{~km}^{3}$ [Hopkins et al., 1998a], implying that strong gradients exist and that the system is relatively efficient in evacuating its runoff. This efficiency is favored by the fact that the main flux of fresh water enters along northwestern Italian coast, and that it is carried southward, by the coastal current. Furthermore, the compensatory northward inflow occurs mainly on the eastern, Croatian side of the basin. This cyclonic tendency, between the 
a

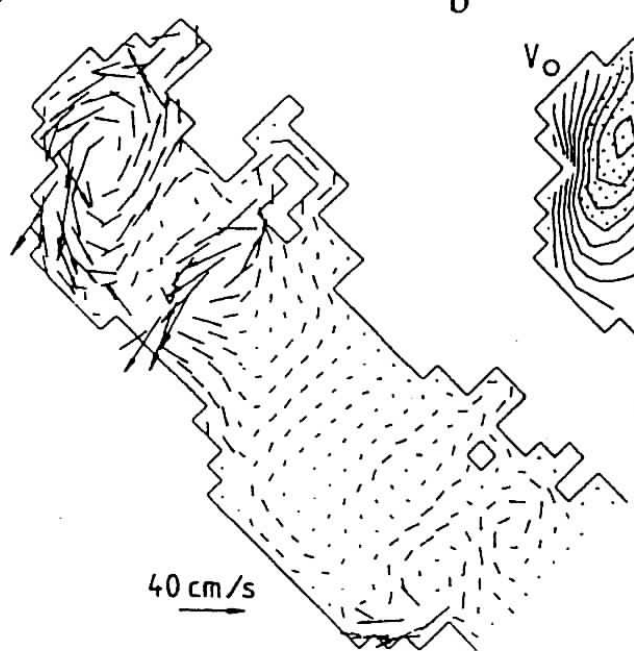

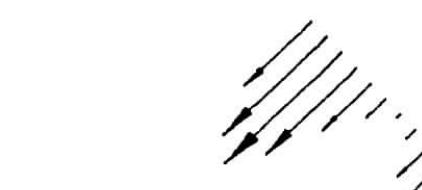

$\mathrm{b}$

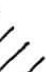

c
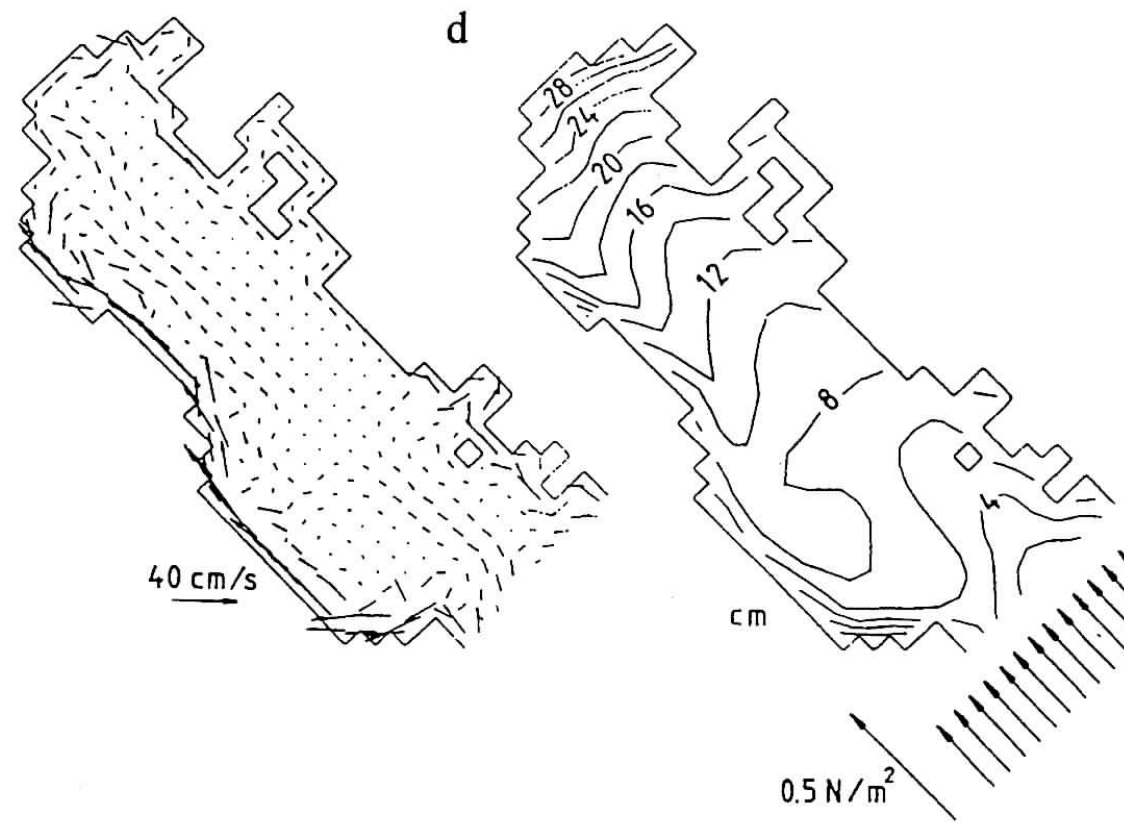

Figure 17. Simulated response of the Adriatic shelf waters to Bora: (a) vertically averaged flow, (b) sea level. Response for sirocco: (c) vertically averaged flow, (d) sea level. V is for Venezia, $R$ for Rovinj, and A for Ancona - see Figure 10. Contouring interval for the bora sea level is $2 \mathrm{~cm}$, with negative values shaded (modified after Orlić et al., 1994). 

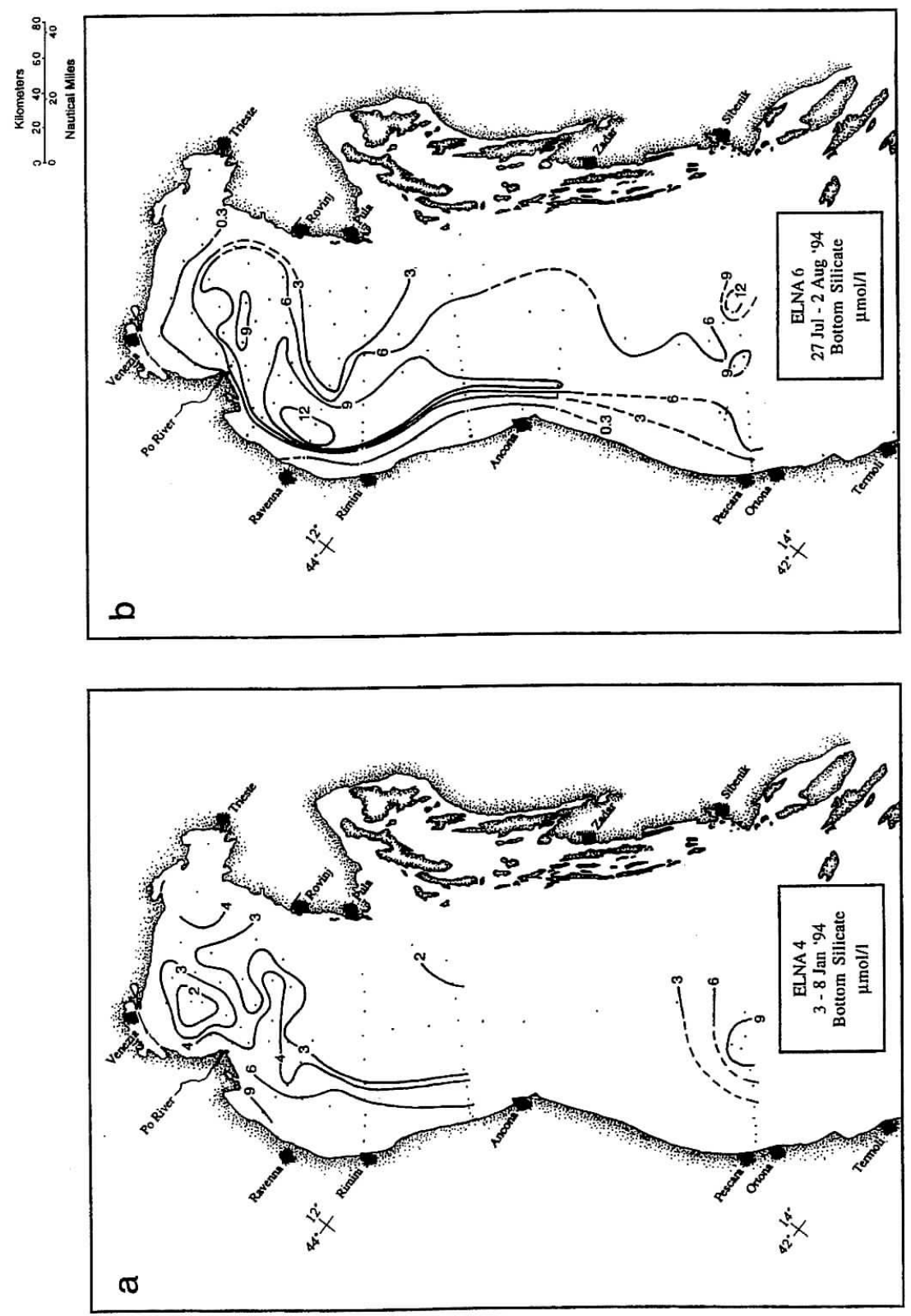

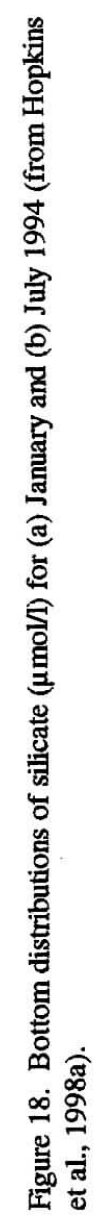

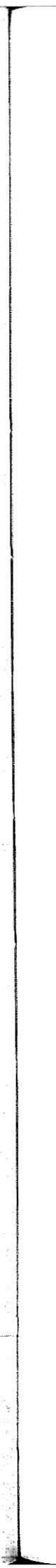


inflow and outflow in the Northern Adriatic, maintains strong westward gradients in salinity that characterize the basin.

The weak annual buoyancy balance masks the fact that on a seasonal scale, the Adriatic is exposed to both very strong riverine runoff (Figure 12) and evaporative-cooling events. As already mentioned, the winter production of dense water is particularly favored in the Northern Adriatic, due to its shallow shelf, which isolates its waters from the heat stored in deep waters, and its exposure to cold and dry continental winds. The occurrence of intense Bora events has already been described as instrumental in the mixing phase of the Northern Adriatic dense water formation. Similar meteorological conditions occurring over the central and southern Adriatic produce an intermediate water mass sufficiently dense to drive the basin's negative thermohaline circulation.

The Adriatic surface-layer circulation seems to be primarily controlled by horizontal density gradients. Horizontal gradients in salinity are derived from the various mixtures of the inflowing (along the eastern coast) and freshwater (from the western coast) sources, which simplifies any assessment of their relative mixture. For example, if the inflowing mean salinity is taken as a reference salinity, then the percentage of freshwater mixture can indicate the relative exposure to discharge waters. For this reason, significant correlations occur between freshwater content and nutrients, chlorophyll, and even productivity. Winter and summer distributions of freshwater content are shown in Figure 14. In January, as indicated by the $<10 \mathrm{~cm} \mathrm{~m}^{-2}$ contour, the inflowing waters penetrate the entire eastern half of the basin, extending to the northern coast (excluding the Gulf of Trieste, which has a local runoff from the Isonzo River). In contrast, the July distribution shows an accumulation of at least $0.5 \mathrm{~m}$ throughout the entire eastern region. The $100 \mathrm{~cm} \mathrm{~m}^{-2}$ isoline is taken to approximate the boundary between the coastal current waters and those mixed into the interior.

Vertical gradients also depend on the relative mixture of the source waters. In addition, they are maintained by the inhibition to mixing provided by the vertical temperature gradients. Thus, lateral and vertical distributions of the fluvial discharges are primarily reflected in the salinity distribution and are confined to the western surface layer, which expands and contracts in relation to the intensity of the discharge and the energy available for mixing. However, analyzing nine years of weekly averaged sea surface temperature data (at spatial resolution of $18 \mathrm{~km}$ ) Gacić et al. [1997] identified a prominent thermal signature of the western surface outflow (influenced by the Po discharge) with a large longitudinal SST gradient of $5^{\circ} \mathrm{C}$ between the (colder) northernmost part of the Adriatic and the vicinity of the Otranto Strait. Interannual analysis of the same data set helped identify variability in the northward extension of warm waters along the eastern coast, which in some years could reach the northernmost parts of the Adriatic. Barale et al. [1986] analyzed monthly averages of the Coastal Zone Color Scanner (CZCS) pigment concentration fields. He found the width of the western coastal layer, north and south of the Ancona headland, negatively correlated with the Po discharge: decreasing runoff was accompanied by thickening of the western coastal layer, whereas increasing runoff corresponded to a thinner one. The authors rationalized the result within the dynamical framework of vortex stretching and bottom friction balance.

Solar heating can be considered evenly distributed, therefore not contributing to any strong horizontal gradients, as observed in salinity. Two secondary effects, however, do affect the surface layer thermal structure. One stems from the surface turbidity correlation with the concentration of freshwater (either directly, due to the discharged particulates, or indirectly, due to productivity) and with elevated surface temperatures. The other is brought about by the difference between the riverine and the Northern Adriatic waters. Multiannual monthly 
averages of the Po River temperature measured at Pontelagoscuro and the Northern Adriatic temperatures registered at the island of Sveti Ivan (near Rovinj) show that riverine and shelf waters can differ by as much as $7^{\circ} \mathrm{C}$ in winter months. However, one should recall that in winter, the cold and fresh Po waters are confined within a narrow coastal boundary layer; strong episodes of Bora wind can provoke offshore spreading [Zore-Armanda and Gacić, 1987, Sturm et al., 1992]. The difference disappears in late March/April at the onset of spring warming, and in August/September when autumn cooling starts [Sturm at al., 1992].

As in the Chesapeake Bay estuary, stratification is the net result of competing forces that create buoyancy and mixing forces that destroy it. In the Northern Adriatic, in areas without appreciable freshwater addition, thermal stratification proceeds seasonally, as a function of solar insolation. Winter convection is sufficient to turnover the water almost everywhere in the basin; in areas where the surface salinity remains low enough, the salinity stratification will persist throughout the winter. This results in large horizontal differences in the depth of the mixed layer (Figure 19) and it is conducive to winter blooms within the WAC [Totti et al., 1996]. For the same reason, the summer pycnocline is considerably stronger in western areas due to this additional buoyancy. The pycnocline can develop a broad, deep or double structure, depending on its relative exposure to buoyancy input and to mixing energy (Figure 19). The situation can be also viewed at the climatological scale (Figure 20). In spring, surface heating builds up the seasonal thermocline, while snow melting in the Alps usually provides a spring runoff maximum (Figure 12) and fresh water to fill the surface layer, further reinforcing the stratification. Temperature differences between the surface and bottom layers can reach $6^{\circ} \mathrm{C}$, while surface horizontal salinity gradients can be traced well into the basin interior; high salinity waters occupy the bottom layer. As heating proceeds in summer, vertical temperature gradients are further strengthened; a halocline can be observed although the summer discharge is typically low.

\section{Ecological implications}

Any study of the Northern Adriatic ecosystem variability inevitably requires some insight into its physical environment. Chemical and biological processes occur in a moving, eddying and diffusing environment; to understand how they interact with the physical system requires understanding of water masses and physical and dynamical properties on many spatial and temporal scales. Nutrient cycles in the Northern Adriatic, are under simultaneous influence of the Po River discharge, the varying stability of the water column and the strength of the horizontal circulation. Both stability and circulation are affected by the discharge, and all three of them by meteorological conditions. Synergistic interplay of all these factors affects the degree of eutrophication in the Northern Adriatic, and occasionally produces harmful hypoxic/anoxic conditions in the bottom waters.

Two cases are particularly revealing. It has been already pointed out that in late autumn and winter thermal and evaporative losses to the atmosphere bring about more rapid cooling. The surface cooling as well as wind-induced intermittent mechanical mixing maintain instability of the water column, and vertically homogeneous motions prevail [Franco and Michelato, 1992; Artegiani et al,, 1997]. These buoyancy sinks also lead to denser water and a lower sea level than in the Middle Adriatic. This difference supports a northward flow along eastern coast and promotes intrusion of oligotrophic, higher salinity and well-oxygenized 

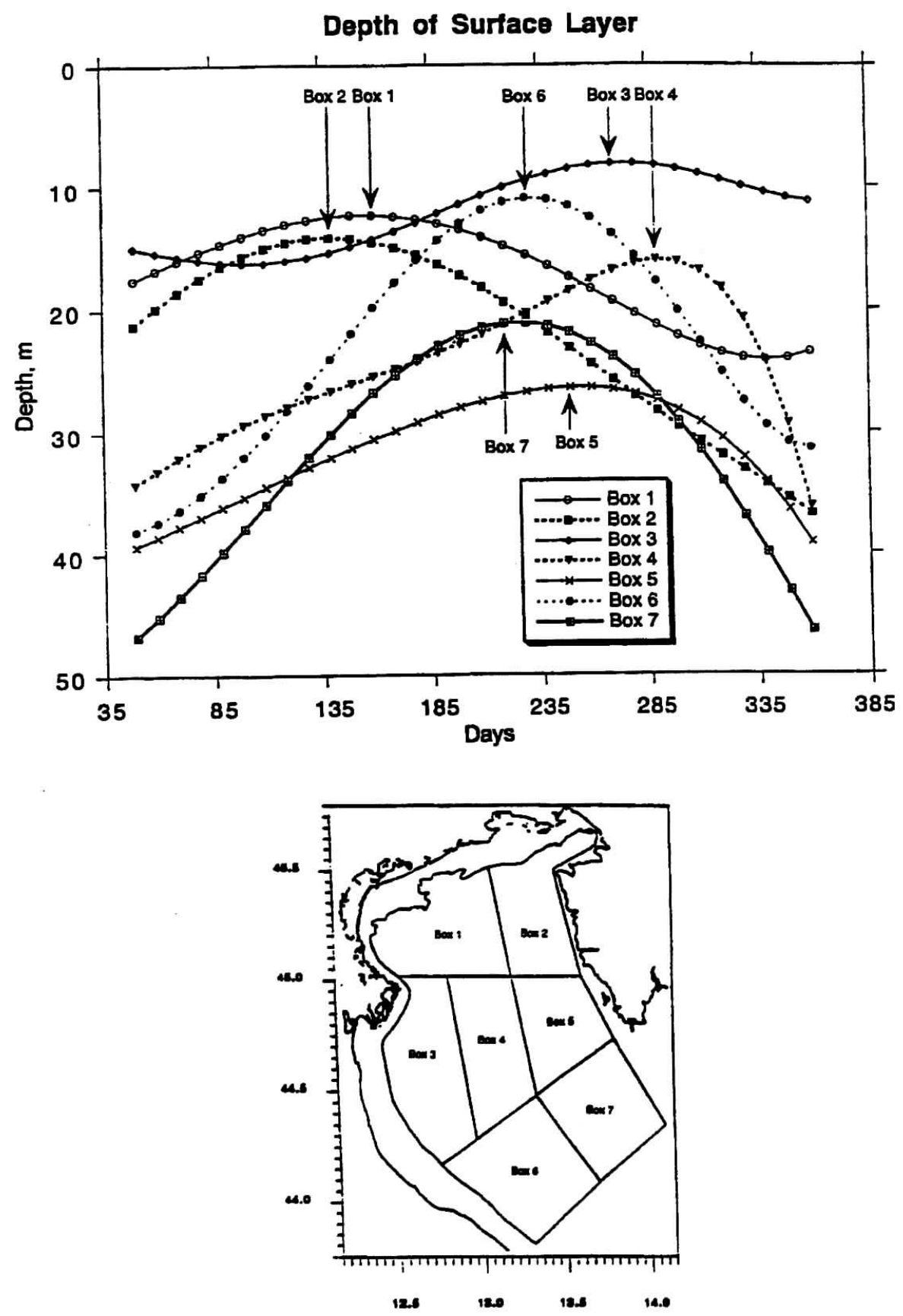

Figure 19. Depth of the average mixed layer and depth of the pycnocline (m) averaged over seven subareas of the Northern Adriatic, from Hopkins et al. (1998a) 


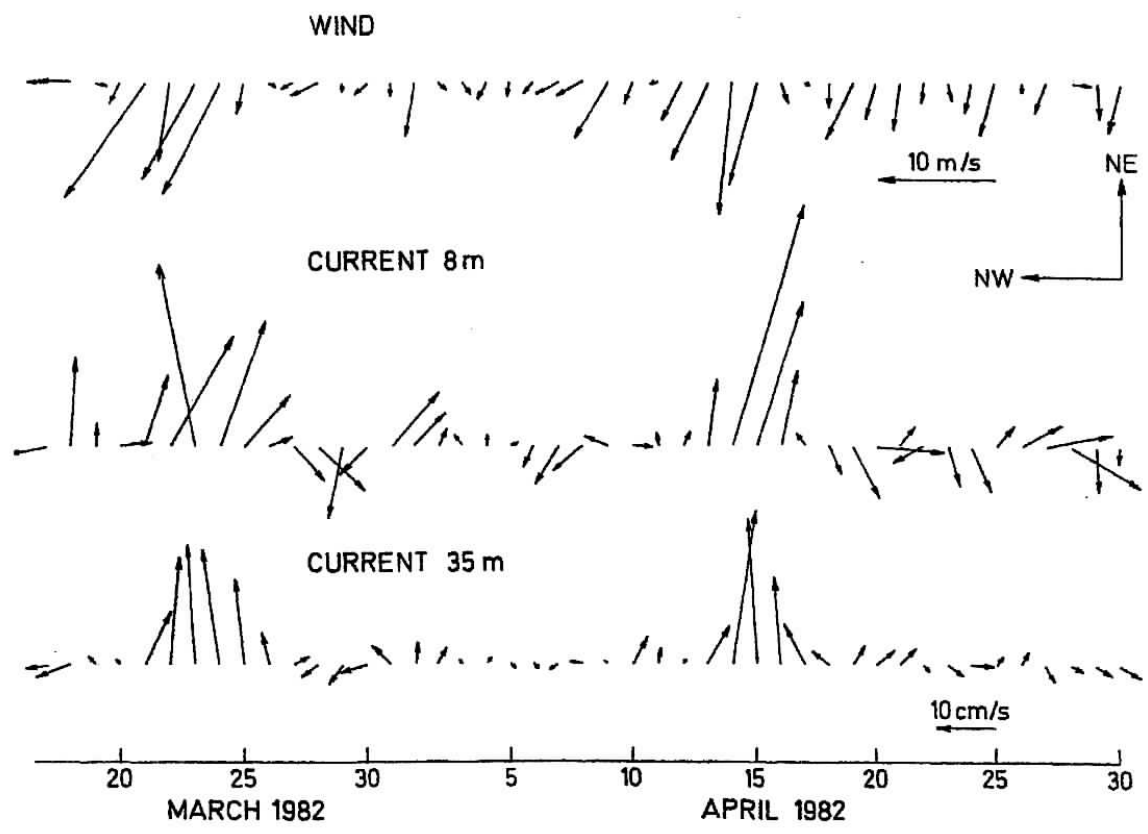

Figure 20. Twenty-nine year (1966 - 1994) averaged vertical distribution of temperature and salinity in (a) May, and (b) August at the Rovinj - Po transect (see Figure 10).

Middle Adriatic waters. The return southward flow along the Italian coast keeps the Po outflow pressed to the western shore and helps the export of excessive nutrients. The pronounced autumn peak in the Po River runoff (Figure 12) can produce significant fresh water accumulation, and an associatedspreading towards eastern shore. In late spring and summer, a progressive accumulation of heat leads to the development of a sharp thermocline and a pronounced stratification, further supported by fresh- water addition. A strong pycnocline effectively insulates the bottom waters from the surface layer, impairing oxygen transport. Steric height changes lead to flattening of the sea level topography, which works against an entry of Middle Adriatic waters into the Northern Adriatic.

The Northern Adriatic cyclonic gyre is commonly observed in late summer and autumn; its southern part can help advect the low-salinity, nutrient-rich Po river waters towards the eastern margin. In June 1977, unusually high levels of organic production in the eastern part of the Northern Adriatic was accompanied by extremely low oxygen concentrations in the bottom water, these conditions persisted throughout September. During spring and summer, unusually low salinities, rarely observed in the eastern part of the Northern Adriatic, were also observed in the 5-10 m deep surface layer [Degobbis et al., 1979]. A series of phytoplankton blooms occurred, generating excessive organic matter, which then sedimented and decomposed in bottom waters. The oxygen content of the surface layer was high (including the east Northern Adriatic), but below a highly stable pycnocline a pronounced oxygen depletion developed. In the western part, bottom oxygen saturation reached a record low (13\%). A different situation developed in the summer of 1988. No excess discharge of fresh 
water took place. Rather low surface salinities were measured southeast of the Po River Delta, but values close to multi-annual averages were registered at other stations. Apparently, in contrast to 1977 when the halocline was pronounced, in 1988 temperature was the primary contributor to vertical density gradients. Nevertheless, the bottom oxygen saturation in the western and central parts of the basin reached the 1977 record lows [Degobbis et al. 1991]. Degobbis hypothesized a reduced inflow of Central Adriatic waters as well as strengthened stratification, promoted by extremely calm, dry and warm weather from May to the end of August. In winter however, as both the December 1977 and December 1988 cases testify, the system was reinitialized, and oxygen renewed throughout the Northern Adriatic, the result of increased advection from the Central Adriatic and improved convective mixing as well as reduced consumption. During the 1977 atmospheric conditions of extremely low barometric pressure and increased rainfall, very high Po water discharges "flooded" the entire area. The freshwater accumulation, from late winter to late fall, markedly increased the stratification of the water column. As a consequence, salinities much lower than the historical minima were observed in the upper water column (5-15 m depth), particularly in the eastern part of the northern Adriatic [Degobbis et al., 1979]. Massive riverine nutrient discharges greatly increased the production and decomposition rates of organic matter. The excess supply of organic matter to the sediment caused a higher than normal oxygen demand and created near-anoxic conditions (oxygen saturation ratios 13-40\%) below the highly stable pycnocline over the most part the year [Degobbis et al., 1979]. Eventually in November, anoxia developed over an extended area [Stefanon and Boldrin, 1980].

A different situation developed in 1988 and 1989, when no excess discharge of freshwater took place. Low surface salinities were measured southeast of the Po River Delta, but values close to multi-annual averages were registered at other stations. Apparently, in contrast to 1977 when halocline was pronounced, in 1988 and 1989 thermocline primarily contributed to the vertical density gradients. During the most part of the year (except some spring blooms in the western areas), the phytoplankton activity was lower than usual, particularly during the autumn. Nevertheless, in this season the bottom oxygen saturation in the bottom layer of the basin reached the 1977 record lows, culminating in mid-November anoxic conditions over an area of $4000 \mathrm{~km}^{2}$ [Degobbis et al., 1991; Degobbis et al., 1993; Hrs-Brenko et al., 1994]. It was hypothesized that reduced inflow of Central Adriatic waters and strengthened stratification occurred during long periods of extremely calm, dry and warm weather, brought about by prolonged and unusually high barometric pressure over the area [Crisciani et al., 1994; Randic et al., 1996]. Current velocity statistics for the eastern northern Adriatic show reduced magnitudes during "critical" late spring periods in 1988 and 1989 compared to 1986 and 1987 years [Degobbis et al., 1991]. In these conditions, the residence time of nutrients and their effects on the ecosystem of the region obviously were greatly increased. In December of both 1977 and 1989, with increased advection from the Central Adriatic, and improved convective mixing the system reinitialized, and oxygen increased throughout the Northern Adriatic.

\section{Comparisons}

\section{Circulation}

The Chesapeake Bay and Northern Adriatic Sea share both a common problem and a common cause--overenrichment of nutrients delivered by rivers draining watersheds where 
man has profoundly altered the landscape. These rivers in turn drive a thermohaline circulation in the receiving water body that determines nutrient pathways and regulates vertical exchange.

While there is a similarity in structure and function of the circulation along the axis of the two water bodies of interest, the marked difference in width has important consequences for both vertical exchange and horizontal flow. For the majority of Chesapeake Bay, the width does not greatly exceed the internal Rossby radius. Only over the southern portion of the Bay is the width sufficient to allow lateral separation of structure and flow, with the fresher water confined by rotation to the western shore, often as a recognizable coastal current. The large buoyancy inputs to the Northern Adriatic also are confined to the western shore, but the width of the Sea is far greater than the internal Rossby radius along its entire length. This geometry allows for marked lateral gradients in stratification, especially between the Italian Coastal Current in the interior. In addition, the width allows for the existence of countercurrents over the eastern part of the domain, developing the general cyclonic circulation of the Adriatic. Perhaps even more important, the geometry also allows for regional circulation cells or gyres, especially during strong wind forcing.

In both systems, buoyancy-driven flows are significantly modulated on scales of days to months by the action of the wind. In Chesapeake Bay, the winds drive both an internal circulation and a quarter-wave seiche, both of which constitute the dominant subtidal variability in flow. At any time of the year, wind forcing may reach the point where the Bay destratifies, but the strong winds of winter create more occasions than in summer. In the Northern Adriatic, when the Bora or Sirocco appear (primarily in winter), they not only dominate the surface circulation, but they also affect the large-scale thermohaline circulation as a result of air-sea interactions.

As buoyancy sources and wind patterns evolve through the seasons, the Chesapeake Bay and Northern Adriatic undergo a parallel progression in stratification and circulation (along with many coastal bodies of water). Spring brings an increased delivery of buoyancy from runoff, precipitation, and heating. Localized sources of buoyancy create spatially heterogeneous density fields and associated thermohaline circulations. As the seasons move through summer to autumn and winter, buoyancy sinks--evaporation and cooling--contribute more to the circulation, although a pronounced peak in the Po River runoff can produce significant fresh water accumulation, and its spreading towards eastern shore of the Northern Adriatic. The decrease in stratification created by buoyancy sinks sets up conditions that facilitate vertical mixing by the stronger winds during these seasons. These winds can create short intervals of destratification in the Chesapeake Bay, but more prevalent homogeneous water columns in the Northern Adriatic. It also leads to denser water and lower sea level than in the Middle Adriatic. The difference supports a northward flow along eastern coast and promotes intrusion of oligotrophic, higher salinity and well oxygenated Middle Adriatic waters. This flow, together with the return southward flow along the Italian coast provides a complete cyclonic circulation, and helps the export of excessive nutrients. In summer, steric height changes commonly lead to flattening of the sea level topography, which works against the entry of Middle Adriatic waters into the Northern Adriatic. On the western side the sea level contours follow the bathymetry of the Italian coast, decreasing offshore and to the south and sustaining geostrophic coastal convergence. The cyclonic tendency between the inflows and outflows in the Northern Adriatic maintains strong westward gradients in salinity that characterizes the basin. 
Hydraulic control points have been identified in the Chesapeake Bay, where the gravitational circulation is regulated, especially during surges in river flow. In the Northern Adriatic, the connection to the remainder of the Adriatic and the Ionian and Mediterranean Sea beyond is less a process of regulation such as a valve at an identified control point than a process of insulation via the long diffusive and transport distances. When the Western Adriatic Current is active, it can provide a short-circuit bypass for the Po River outflow. The Strait of Otranto provides the most clearly defined control point, but it is well removed from the Northern Adriatic. Although the large length-to-width aspect ratio of the Chesapeake Bay also acts to insulate the inner reaches from the lower Bay and the continental shelf beyond, there are both internal control points created by the topography and a comparatively narrow entrance, limiting exchange with the coastal ocean. The size and bounded nature of both water bodies contribute to retention. The residence time for Chesapeake Bay is on the order of 7 months, based on fresh water fraction. Although the residence time for the Adriatic as a whole is estimated to be of the order years [Mosetti, 1990], the retention for the shallow Northern Adriatic is expected to be considerably shorter, perhaps as short as 2-3 months [Hopkins, 1998].

\section{Nutrient Pathways and Oxygen Depletion}

Although there are a variety of sources, the primary delivery mechanism for nutrients in both the Chesapeake Bay and the Northern Adriatic is a river discharging near the landward end of the water body. In the Chesapeake Bay, the river not only feeds the spring phytoplankton bloom, but it also contributes buoyancy and hence, stratification. This stratification, which covers the entire width over the major portion of the Bay, suppresses vertical exchange and contributes to the severe oxygen depletion in summer. Where the Susquehanna River in Chesapeake Bay can be viewed as a nearly one-dimensional point source for the upper Bay, the Po River's contribution to the Adriatic is more a line source, with nutrients feeding into the interior through lateral exchange from the Western Adriatic Current [Hopkins, 1998]. For the Northern Adriatic, the situation is more complex, with nutrients entering through direct exchange from the turning region of the Po River plume, and from more-diffuse inputs from the Italian Coastal Current via recirculation in the interior.

The confined geometry of the Chesapeake Bay is not only more conducive to oxygen depletion, but also the monitoring this phenomenon. Here, analysis of monitoring data indicates that the primary determinant of interannual variability is late-spring runoff, which controls stratification during the summer depletion interval, which typically peaks in late July. Recent work indicates an underlying upward trend in oxygen depletion, paralleling the trend in nutrient loading. For the Northern Adriatic, the basin does not act to contain the lower layer waters as does the paleochannel of the Chesapeake Bay. For this reason, any developing zones of oxygen depletion are vulnerable to reaeration via advection of oxygenated Middle Adriatic waters from a variety of directions. This advection, in turn, is subject to a substantial amount of variability ranging from event-scale to interannual.

Deciphering the details of nutrient pathways in either the Chesapeake Bay or the Northern Adriatic will require concerted effort. Water motion plays crucial roles throughout the cycle, from initial delivery via multiple sources, to transport and dispersion, to uptake by phytoplankton and the regulation of recycling. In both water bodies, the limiting uncertainties are the mechanisms and quantitative rates of vertical exchange. While this lack is shared with the open ocean, a particular concern in these shallow coastal systems is the role of singularities 
in vertical exchange over abrupt changes in bottom topography. Lateral mixing is also important in both systems. In the Chesapeake Bay, the exchange between the central channel and flanking shoals is of great interest, but at present poorly known.

If physical oceanography is to contribute to solving the Northern Adriatic ecological problems, further progress is required along several lines of research. While elucidation of circulation, transport and mixing processes at a range of spatial and temporal scales requires development and refinement of numerical models, much improved observational system is also needed to tie the model results to reality. In turn, both the design of field experiments and the analysis of the observational data can profit from a dynamical framework and integrative power of models. Observational capabilities should include autonomous moorings, shipboard instrumentation, GPS drifters, as well as spaceborne sensors. Key variables (temperature, salinity, currents, dissolved oxygen, and pigment concentration) should be recorded synoptically at less-resolved basin-wide scale, as well as collected at selected locations with higher temporal resolution and over prolonged periods of time. Coupling assimilative and/or process oriented models with observations should also accommodate the need to meld the empirical data from various sources. It is worth reiterating here that in order to exploit the full potential of such an endeavour a better collaboration across disciplines is indispensable.

\section{References}

Accerboni, E. and B. Manca, Storm surges forecasting in the Adriatic Sea by means of a twodimensional hydrodynamical numerical model, Boll. Geofis. Teor. Appl., XV, 3 - 23, 1973.

Accerboni, E., B. Manca, A. Michelato and P. Zennaro, Richerche sulla dinamica dell' inquinamento marino dell' Adriatico settentrionale: approccio metodologico e primi risultati, Atti Conv. Sci. Naz. Progr. Final. Oceanogr. Fondi marini, Roma, 1057-1080, 1979.

Accerboni, E., B. Manca, A. Michelato, F. Moro and R. Mosetti, Caratteristiche dinamiche estive dell'Alto Adriatico e loro influenza sui fenomeni di inquinamento, Convegno delle Unita Operative Afferenti ai Sottoprogetti, Risorse Biologiche e Inquinamento Marino, Roma, 891-912, 1981.

Artegiani, A., E. Paschini, A. Russo, R. Pariante and C. Totti, Seasonal evolution of the physical and biochemical water properties observed from the Senigallia transect, In: Ecosystems Research Report, the Adriatic Sea, EU/Environment Series, Brussels, 1997.

Barale, V., C. R. McClain and P. Malanotte-Rizzoli, Space and time variability of the surface color field in the northern Adriatic Sea, J. Geophys. Res., 91, 12957-12974, 1986.

Beardsley, R.C. and W.C. Boicourt, On estuarine and continental shelf circulation in the Middle Atlantic Bight, in Evolution of Physical Oceanography, edited by B. A. Warren and C. Wunsch, pp. 198233, The MIT Press, Cambridge, MA, 1981.

Boicourt, W.C., A numerical model of the salinity distribution in upper Chesapeake Bay, The Johns Hopkins University Technical Report 54, Ref. 69-7, Chesapeake Bay Institute, Baltimore, 59 pp, 1969.

Boicourt, W.C., The circulation of water on the continental shelf from Chesapeake Bay to Cape Hatteras, Ph.D. Thesis, The Johns Hopkins University, Baltimore MD, 183 pp., 1973.

Boicourt, W. C., The detection and analysis of the lateral circulation in the Potomac River estuary, Maryland Power Plant Siting Program Technical Report PPRP-66, 209 pp., 1983.

Boicourt, W.C., Circulation in the Chesapeake Bay entrance region: estuary-shelf interaction, in Chesapeake Bay Plume Study: Superflux 1980, edited by J.W. Campbell and J.P. Thomas, pp. 61-78, National Aeronautics and Space Administration. Conf. publ. 2188., 1980.

Boicourt, W.C. , Recruitment dependence upon planktonic transport in the coastal ocean, in Towards a Theory of Biological-Physical Interactions in the World Ocean, edited by B. Rothschild, pp. 183202, Kluwer Academic Publishers, 1988. 
Boicourt, W.C., The influences of circulation processes on dissolved oxygen in Chesapeake Bay, in Dissolved Oxygen in Chesapeake Bay, edited by D. Smith, M. Leffler and G. Mackiernan, pp. 7-59, Maryland Sea Grant, College Park, MD, 1992.

Brambati, A., Origin and evolution of the Adriatic Sea, pp. 5-24 In: $25^{\text {th }}$ European Marine Biology Symposium, University of Ferrara, 1990.

Brandt, A., C.C. Sarabun, H.H. Seliger and M.A. Tyler, The effects of a broad spectrum of physical activity on the biological processes in the Chesapeake Bay, in Marine Interfaces Ecohydro-Dynamics, edited by J.C.J. Nihoul, pp. 361-384, Elsevier, Amsterdam, 1986.

Browne, D. and Carl W. Fisher, Tide and tidal currents in the Chesapeake Bay, National Oceanographic and Atmospheric Administration Technical Report NOS OMA3, 143 pp., 1988.

Buljan, M. and M.Zore-Armanda, Oceanographical properties of the Adriatic Sea, Oceanogr.Mar. Biol. Ann. Rev., 14, 11-98, 1976.

Bue, C.D., Monthly surface-water inflow to Chesapeake Bay, U.S. Geological Survey Water Resources Division Open File Report, 1968.

Cavallini, F., A three-dimensional numerical model of tidal circulation in the Northern Adriatic Sea, Boll. Oceanol. Teor. Appl., 3, 205-218, 1985.

Cerovecki I., M. Orlić and M. C. Hendershott, Adriatic seiche decay and energy loss to the Mediterranean, Deep-Sea Res. I, 44, 2007 - 2029, 1997.

Chao, S.-Y., Wind-driven motion near inner shelf fronts, J. Phys. Ocean., 92, 3849-3860, 1987.

Chao, S-Y. and W.C. Boicourt, Onset of estuarine plumes, J. Phys. Ocean., 16, 2137-2149.1986.

Chao, S.-Y. and T. Paluszkiewicz, The hydraulics of density currents over estuarine sills, J. Phys. Ocean., 96, 7065-7076, 1991.

Chuang, W.-S. and W.C. Boicourt, Resonant seiche motion in the Chesapeake Bay, J. Geophys.Res. 94, 2105-2110, 1989.

Colman, S.M., J.P. Halka, C.H. Hobbs, R. B. Mixon and D.S. Foster, Ancient channels of the Susquehanna River beneath Chesapeake Bay and the Delmarva Peninsula, Geol.Soc. Amer. Bull.,102, 1268-1279, 1990.

Crisciani, F., S. Ferraro and F. Raicich, Evidence of recent climatic anomalies at Trieste (Italy), Climat. Change, 28, 365-374, 1994.

Cronin, W. B., Volumetric, areal, and tidal statistics of the Chesapeake Bay and its tributaries, The Johns Hopkins University Chesapeake Bay Institute Special Rep. 20, Ref. 71-2, 135 pp., 1971.

Defant, A., Physical Oceanography, Vol. 2, 598 pp., Pergamon Press, Oxford, 1961.

Degobbis, D., Increased eutrophication of the Northem Adriatic Sea. Second act, Mar. Pollut. Bull., 20, 452-457, 1979.

Degobbis, D., N. Smodlaka, I. Pojed, A. Krivanic and R. Precali, Increased eutrophication of the Northern Adriatic Sea, Mar. Pollut. Bull., 10, 298-301, 1979.

Degobbis, D., I. Ivančić, R. Precali and N. Smodlaka, Unusual oceanographic conditions in the area of northern Adriatic Sea during 1989. 1. Oceanographic properties, nutrient cycle and the fall bottom layer anoxia (in Croatian), Hidrografski godinjak 1989, 27-47, 1991.

Degobbis, D., A. Travizi and A. Jaklin, Meccanismi di formazione di strati di fondo ipossici e anossici nel bacino dell'Alto Adriatico setentrionale e reaziioni delle comunita bentoniche, in Ipossie e Anossie di Fondali Marini L'Alto Adriatico e il Golfo di Trieste, Regione Autonoma Friuli-Venezia Giulia, Direzione Regionale dell' Ambiente, edited by G. Orel, S. Fonda-Umani, and F. Aleffi, pp. pp. 57-62, 1993.

Dyer, K.R., Estuaries: A Physical Introduction, Wiley and Sons, New York, 140 pp., 1973.

Dyer, K.R., Lateral circulation effects in estuaries, pp. 22-29 In: Estuaries, Geophysics and the Environment, National Research Council National Academy of Sciences, Washington, 1977.

Farmer, D.M. and H.J. Freeland, The physical oceanography of fjords, Progr. Oceanogr., 12, 147-220, 1983.

Feruglio, G., Risultati di esperience con gallegianti per lo studio delle correnti del Mare Adriatico negli anni 1910-1914, 92 pp., R. Comitato Talassografico Italiano, Memoria LV, 1920.

Franco, P., Oceanography of northem Adriatic Sea, 1: Hydrologic features, Cruises July-August and October-November 1965, Archo Oceanogr. Limnol., Suppl. 16, 1-93, 1970.

Franco, P., Oceanography of northern Adriatic Sea, Cruises January-February and April-May, 1966, Archo Oceanogr. Limnol., Suppl. 17, 1-97, 1972. 
Franco, P., L. Jeftić, P. Malanotte-Rizzoli, A. Michelato and M. Orlić, Descriptive model of the Northern Adriatic, Oceanol. Acta, 5, 379-389, 1982.

Franco, P. and A. Michelato, Northern Adriatic Sea: oceanography of the basin proper and of the western coastal zone, Sci. Total Environ., Suppl., 35-62, 1992.

Furlan, D., The climate of southeast Europe, World Surv. Climatol. 6 185-235, 1977.

Gačic, M., S. Marullo, R. Santoleri and A. Bergamasco, Analysis of the seasonal and interannual variability of the sea surface temperature field in the Adriatic Sea from AVHRR data (1984 - 1992), J. Geophys. Res., 102, 22937 - 22946, 1997.

Godin, G. and L. Trotti, Trieste water levels 1952-1971, Miscellaneous Special Publication, Fisheries and Marine Service, Ottawa, No. 28, 24 pp.,1975.

Goodrich, D.M., On meteorologically induced flushing in three U.S. east coast estuaries, Estuar. Coast. Shelf Sci., 26, 111-121, 1988.

Goodrich, D.M., W.C. Boicourt, P. Hamilton and D.W. Pritchard, Wind-induced destratification in Chesapeake Bay, J. Phys. Ocean.,17, 2232-2240, 1987.

Goodrich, D.M. and A.F. Blumberg, The fortnightly mean circulation of Chesapeake Bay, Estuar. Coast. Shelf. Sci., 32, 451-462, 1991.

Grancini, G. and B. Cescon, Dispersal processes of freshwaters in the Po River coastal are, Limnol. Oceanogr., 18, 705-710, 1973.

Haas, L.W., The effect of the spring-neap tidal cycle on the vertical salinity structure of the James, York and Rappahannock Rivers, Virginia, U.S.A., Estuar. Coast. Mar. Sci. 5, 485-496, 1977.

Hayward, D., C.S. Welch and L.W. Haas, York River destratification: An estuary-subestuary interaction, Science 216, 1413, 1982.

Hendershott, M.C. and P. Rizzoli, The winter circulation of the Adriatic Sea, Deep-Sea Res., 23, 353 $370,1976$.

Hicks, S.D., Tidal wave characteristics of Chesapeake Bay, Chesapeake Science, 5, 103-113, 1964.

Hopkins, T. S., Scientific results of the ELNA project. So. Pro. Mar. S.P.A., Fiumicino, Rome, Italy, 115 pp., 1996.

Hopkins, T. S., Physical control of the eutrophic response in the Northern Adriatic, illustrated by a nitrogen budget from ELNA data, Annali dell'Istituto Superiore di Sanita', 1998.

Hopkins, T.S., Physical processes in Mediterranean estuaries, pp. 269-310 In: B. Kjerfve (ed). Transport Processes in Estuarine Environments, Seventh Bell W. Baruch Institute for Marine Biology and Coastal Research Symposium, Georgetown, SC, May 1978.

Hopkins, T.S. A. Artegiani, A., F. Bignami and A. Russo, Water-mass modification in the Northern Adriatic, a preliminary assessment from the ELNA data set, In: Ecosystems Research Report, the Adriatic Sea, EU/Environment Series, Brussels, 1998a.

Hopkins, T.S., A. Artegiani, C. Kinder and R.Pariente, Description of the Northern Adriatic circulation as computed from the ELNA hydrography, In: Ecosystems Research Report, the Adriatic Sea, EU/Environment Series, Brussels, 1998b.

Hrs-Brenko, M., D. Medakovic, Z. Labura and E. Zahtila, Bivalve recovery after a mass mortality in the autumn of 1989 in the northern Adriatic Sea, Period. Biol., 96, 455-458, 1994.

Huzzey, L.M. and J.M. Brubaker, The formation of longitudinal fronts in a coastal plain estuary, $J$. Geophys. Res., 93, 1329-1334, 1988.

Ianniello, J.P., Tidally induced residual currents in estuaries of constant breadth and depth, J. Phys. Ocean., 9, 962-974,1977.

Jay, D.A., R.J. Uncles, J. Largier, W.R. Geyer, J. Vallino and W.R. Boynton, A review of recent developments in estuarine scalar flux estimation, Estuaries 20, 262-280, 1997.

Krajcar, V. and M. Orlić, Seasonal variability of inertial oscillations in the Northern Adriatic, Cont. ShelfRes., 15, 1221-1233, 1995.

Kuzmić, M., and M. Orlić, Wind-induced vertical shearing. Alpex Medalpex data and modelling exercise, Ann. geophys., 5B, 103-112, 1987.

Kuzmić, M., Z. Pasarić and M. Orlić, Adriatic shelf response to Scirocco wind - A modelling inquiry, Rapp. Comm. int. Mer. Medit., 31, 212, 1988.

Makjanić, B., Climate of the Adriatic Sea (in Croatian), Pom. Encikl., 3, 201-207, 1976.

Makjanić, B., Bora and sirocco (In Croatian), Prilozi poznavanju vremena i klime SFRJ, 5, 1-56, 1978. Malanotte-Rizzoli, P.and A. Bergamasco, The dynamics of the coastal region of the Northern Adriatic 
Sea, J. Phys. Ocean., 13, 110-5-1130, 1983.

Manca, B., F. Mosetti and P. Zennaro, Analisi spettrale delle sesse dell' Adriatico, Boll. Geofis. Teoretica Appl., 16, 51-60, 1974.

Markgraf, H., Klimatologie des Mittlemeeres, Deutscher Wetterdienst, Hamburg, 99pp., 1961.

Michelato, A., Caratteristiche della circolazione delle acque costiere dell'Emilia-Romagna, Bologna, 310 pp., 1983.

Milliman, J., C. Rutkowski and M. Meybeck, River discharge to the sea, A global river index (GLORI), LOICZ Core Project Office, Netherlands, 125 pp., 1995.

Mosetti, F. and A. Lavenia, Ricerche oceanografiche in Adriatico nel periodo 1966-1968, Boll. Geofis. Teor. Appl., 11, 191-218, 1969.

Officer, C. B., R.B. Biggs, J. L. Taft, L. E. Cronin, M. Tyler and W. R. Boynton, Chesapeake Bay anoxia: Origin, development, and significance, Science 223, 22-45, 1984.

Olson, P., The spectrum of subtidal variability in Chesapeake Bay circulation, Estuar. Coast.Shelf Sci., 33, 527-550, 1986.

Orlic, M., Oscillations of the inertia period on the Adriatic Sea shelf, Cont. ShelfRes., 7, 577-598, 1987.

Orlić, M., M. Gacić and P.E. La Violette, The currents and circulation of the Adriatic Sea, Oceanol. Acta, 15, 2, 109-124, 1992.

Orlić, M., M. Kuzmić and Z. Pasarić, Response of the Adriatic Sea to the Bora and Sirocco forcing, Cont. ShelfRes., 14, 91-116, 1994.

Parker, B.B., Frictional effects on the tidal dynamics of a shallow estuary, Ph.D. Dissertation, The Johns Hopkins University, Baltimore, MD., 292 pp., 1984.

Pigorini, B., Sources and dispersion of recent sediments of the Adriatic Sea, Mar. Geol., 6, 187-229, 1968.

Polli, S., La propagazione delle maree nell'Adriatico, Atti X Conv. Ass. Geof. Italiana, Roma, 1-11, 1960.

Pritchard, D.W., A study of the salt balance in a coastal plain estuary, J. Mar. Res., 13, 133-144, 1954.

Pritchard, D.W., The dynamics structure of a coastal plain estuary, J. Mar. Res., 15, 33-42, 1956.

Pritchard, D.W., Observations of circulation in coastal plain estuaries, in Estuaries, edited by G.H. Lauff, pp. 37-44, American Association for Advancement Science, 1967.

Pritchard, D.W., A note on the Stokes transport in tidal estuaries, in Management of Environment, edited by B. Patel, pp. 217-226, Wiley, Bombay., 1980.

Pritchard, D.W. and S.R. Rives, Physical hydrography and dispersion in a segment of the Chesapeake Bay adjacent to the Calvert Cliffs Nuclear Power Plant. Chesapeake Bay Institute, The Johns Hopkins University, Special Report No. 74, Baltimore, MD. 374 pp., 1979.

Pritchard, D.W. and M.E.C. Vieira, Vertical variations in residual current response to meteorological forcing in the mid-Chesapeake Bay, in The Estuary as a Filter, edited by V.S. Kennedy, pp. 27-65, Academic Press, Orlando, 1984.

Proudman, J., Dynamical Oceanography, Methuen, London, 409 pp., 1953.

Milliman, J., C. Rutkowski and M. Meybeck, River discharge to the sea, A global river index (GLORI), LOICZ Core Project Office, Netherlands, 125 pp., 1995.

Mosetti, F. and A. Lavenia, Ricerche oceanografiche in Adriatico nel periodo 1966-1968, Boll. Geofis. Teor. Appl., 11, 191-218, 1969.

Officer, C. B., R.B. Biggs, J. L. Taft, L. E. Cronin, M. Tyler and W. R. Boynton, Chesapeake Bay anoxia: Origin, development, and significance, Science 223, 22-45, 1984.

Olson, P., The spectrum of subtidal variability in Chesapeake Bay circulation, Estuar. Coast.Shelf Sci., 33, 527-550, 1986.

Orlić, M., Oscillations of the inertia period on the Adriatic Sea shelf, Cont. ShelfRes., 7, 577-598, 1987.

Orlić, M., M. Gačić and P.E. La Violette, The currents and circulation of the Adriatic Sea, Oceanol. Acta, 15, 2, 109-124, 1992.

Orlić, M., M. Kuzmić and Z. Pasarić, Response of the Adriatic Sea to the Bora and Sirocco forcing, Cont. ShelfRes., 14, 91-116, 1994.

Parker, B.B., Frictional effects on the tidal dynamics of a shallow estuary, Ph.D. Dissertation, The Johns Hopkins University, Baltimore, MD., 292 pp., 1984. 
Pigorini, B., Sources and dispersion of recent sediments of the Adriatic Sea, Mar. Geol., 6, 187-229, 1968.

Polli, S., La propagazione delle maree nell'Adriatico, Atti X Conv. Ass. Geof. Italiana, Roma, 1-11, 1960.

Pritchard, D.W., A study of the salt balance in a coastal plain estuary, J. Mar. Res., 13, 133-144, 1954.

Pritchard, D.W., The dynamics structure of a coastal plain estuary, J. Mar. Res., 15, 33-42, 1956.

Pritchard, D.W., Observations of circulation in coastal plain estuaries, in Estuaries, edited by G.H. Lauff, pp. 37-44, American Association for Advancement Science, 1967.

Pritchard, D.W., A note on the Stokes transport in tidal estuaries, in Management of Environment, edited by B. Patel, pp. 217-226, Wiley, Bombay., 1980.

Pritchard, D.W. and S.R. Rives, Physical hydrography and dispersion in a segment of the Chesapeake Bay adjacent to the Calvert Cliffs Nuclear Power Plant. Chesapeake Bay Institute, The Johns Hopkins University, Special Report No. 74, Baltimore, MD. 374 pp., 1979.

Pritchard, D.W. and M.E.C. Vieira, Vertical variations in residual current response to meteorological forcing in the mid-Chesapeake Bay, in The Estuary as a Filter, edited by V. S. Kennedy, pp. 27 65, Academic Press, Orlando, 1984.

Proudman, J., Dynamical Oceanography, Methuen, London, 409 pp., 1953.

Randic, A. et al., 7. Implications of expected climatic changes for the Cres-Losinj islands, in Climatic Change and the Mediterranean, edited by L. Jeftic, S. Ke...keO, and J.C. Pernetta, pp. 431-548, Arnold, Vol. 2, London, 1996.

Redfield, A.C., The influence of the continental shelf on the tides of the Atlantic coast of the United States, J Mar. Res., 17,432-448, 1958.

Ruzecki, E.P. and D.A. Evans, Temporal and spatial sequencing of destratification in a coastal plain estuary, in Lecture Notes on Coastal and Estuarine Studies, edited by M.J. Bowman, C.M. Yentsch, and W.T. Peterson, pp. 368-389, Springer-Verlag, Berlin., 1988.

Sanford, L.P. and W.C. Boicourt, Wind forced salt intrusion into a tributary estuary, J. Geophys. Res., 48, 567-590, 1990.

Schubel, J.R. and D.W. Pritchard, Responses of upper Chesapeake Bay to variations in discharge of the Susquehanna River, Estuaries 9, 236-249, 1986.

Schwab, D.J. and D.B. Rao, Barotropic oscillation of the Mediterranean and Adriatic Seas, Tellus, 35A, 417-427, 1983.

Sguazzero, P., A Giommoni and A. Goldman, An empirical model for the prediction of the sea level in Venice, Technical Report No. 25, IBM Italia, Venice, 69 pp., 1972.

Simpson, J.H. and R.A. Nunes, The tidal intrusion front: An estuarine convergence zone. Est. Coast. Shelf Sci., 13,257-266, 1981.

Simpson, J.H. and W.R. Turrell, Convergent fronts in the circulation of tidal estuaries, in Estuarine Variability, edited by D.A. Wolfe, pp. 139-152, Academic Press, Orlando, 1986.

Simpson, J.H., J. Brown, J. Matthews and G. Allen, Tidal straining, density currents, and stirring in the control of estuarine stratification. Estuaries 13, 125-132, 1990.

Stefanon, A. and A. Boldrin, The oxygen crisis of the northern Adriatic Sea waters in late fall 1977 and its effects on benthic communities, pp. 167-175 In: The Sixth International Scientific Symposium of the World Underwater Federation (CMAS), 1980.

Stone, P.J., Water and salt transport in the lower reaches of the Chesapeake Bay, Masters Thesis, University of Maryland, 138 pp., 1994.

Stravisi, F., Climatic variations at Trieste during the last century, Geofizika, 4, 61 - 76, 1987.

Sturm, B., M. Kuzmić and M. Orlić, An evaluation and interpretation of CZCS-derived patterns on the Adriatic shelf, Oceanol. Acta Vol. 15(1), 13-23, 1992.

Totti, C., A. Ghetti, R. Pariante and T. Hopkins, Biological coherence in the Western Adriatic Current. Ecosystems Research Report, the Adriatic Sea, EU/Environment Series, Brussels, 1996.

Tsimplis, M.N., R. Proctor and R.A. Flather, A two-dimensional tidal model for the Mediterranean Sea, J. Geophys. Res. 100C, 16223-16239, 1995. 
Tyler, M. A. and H. H. Seliger, Annual subsurface transport of a red tide dinoflagellate to its bloom area: water circulation patterns and organism distributions in the Chesapeake Bay, Limnol. Oceanogr. 23, 227-246, 1978.

Vieira, M.E.C., Estimates of subtidal volume flux in mid-Chesapeake Bay, Estuar. Coast. ShelfSci.,21, 411-427, 1985.

Vieira, M.E.C., The meteorologically driven circulation in mid Chesapeake Bay, J. Mar. Res., 44, 473-493, 1986.

Wang, D.P., Subtidal sea level variation in the Chesapeake Bay and relation to atmospheric forcing, $J$. Phys. Ocean., 9, 413-421, 1979.

Wang, D.P. and A.J. Elliott, Nontidal variability in Chesapeake Bay and the Potomac River: Evidence for non-local forcing, J. Phys. Ocean., 8, 225-232, 1978.

Wilson, R.E., M.E.C. Vieira and J.R. Schubel, Tidal rectification in the Peconic Bays estuary, in Estuarine Variability, edited by D.A. Wolfe, pp. 153-160, Academic Press, Orlando, 1986.

Wolf, J. and J. Luksch, Physikalische Untersuchungen in der Adria. Druck und Commissionsverlag von Carl Gerold's Sohn, Wien, 22 pp., 1887

Zimmerman, J.T.F., Topographic generation of residual circulation by oscillatory (tidal) currents, Geophys. Astrophys. Fl. Dyn. 11, 35- 47, 1978.

Zimmerman, J.T.F.,On the Euler-Lagrangian transformation and the Stokes drift in the presence of oscillatory and residual currents, Deep-Sea Res., 26A,505-520, 1979.

Zore, M., On gradient currents in the Adriatic Sea, Acta adriat., 8, 1-38, 1956.

Zore-Armanda, M., Mixing of three water types in the south Adriatic, Rapp. P.-v Réun. Comm int. Explor. scient. Mer médit., 17, 879-885. 1963.

Zore-Armanda, M and Z. Vučak, Some properties of the residual circulation in the Northern Adriatic, Acta adriat., 21, 55-74, 1984.

Zore-Armanda, M. and M. Gačić, Effects of bura on the circulation in the north Adriatic, Ann. Geophys., 5B, 93 - 102, 1987. 


\section{ERRATA CORRIGE}

Figure 20
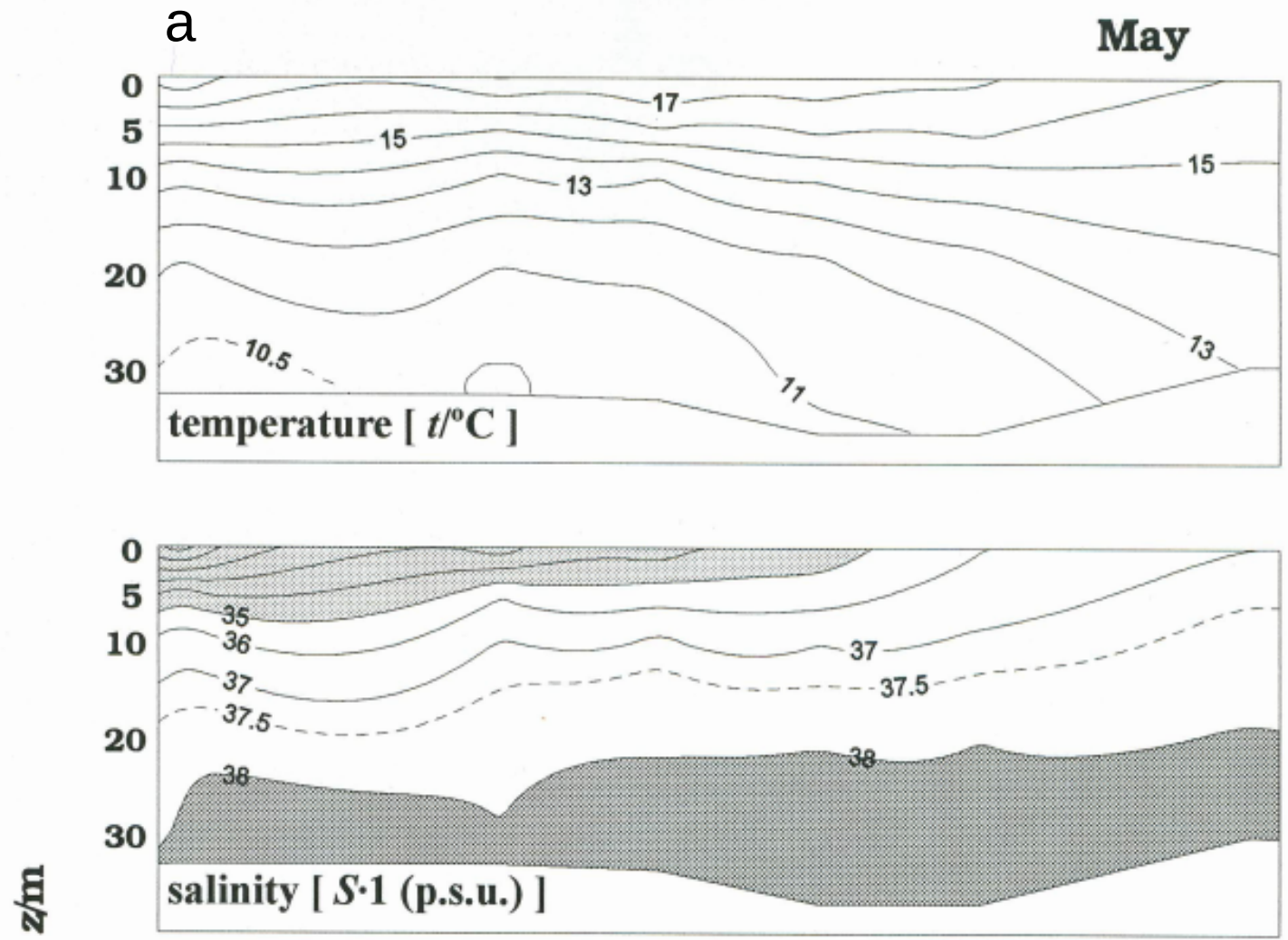

b

August
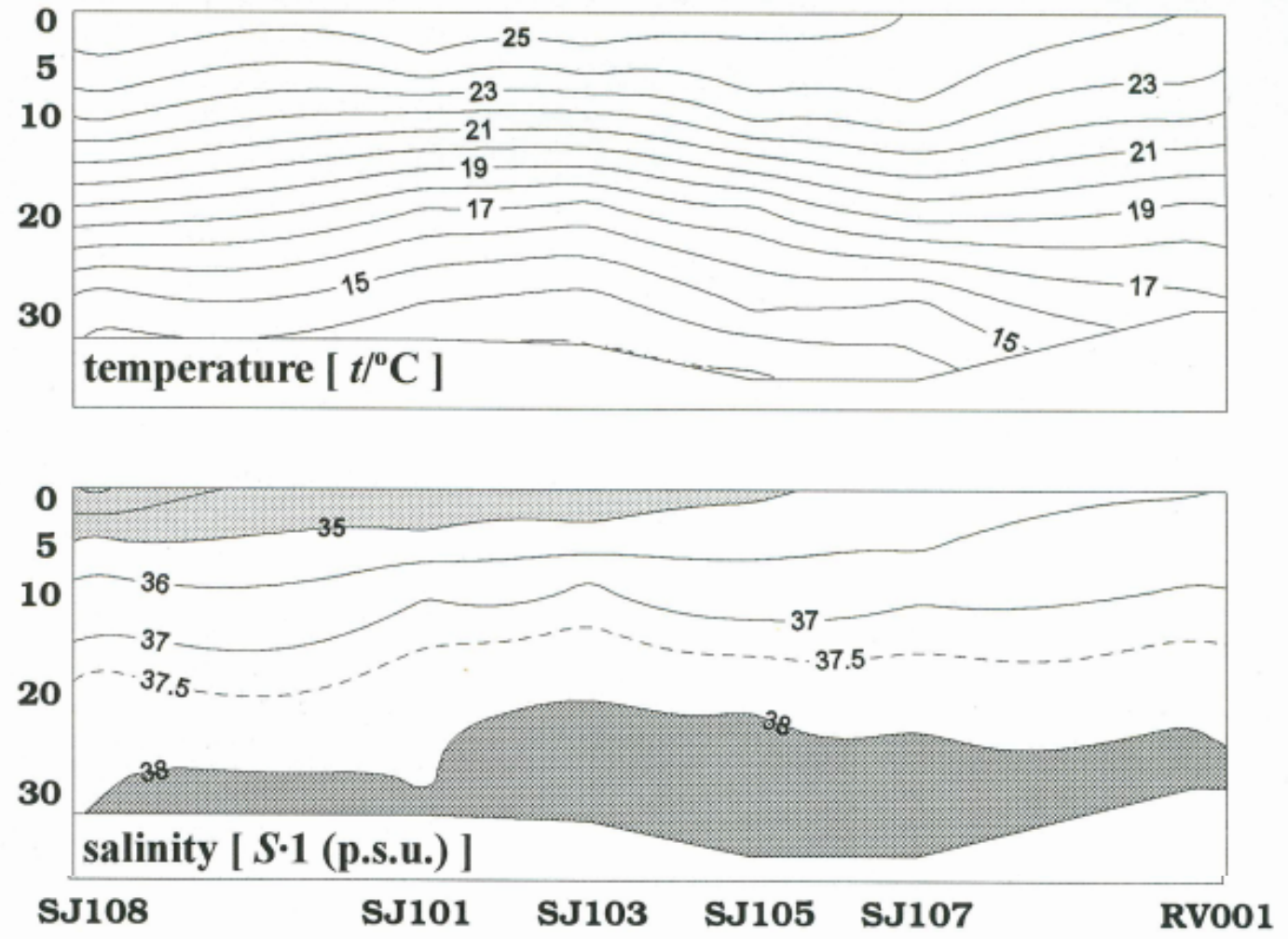